\title{
Mycotoxins Analysis in Cereals and Related Foodstuffs by Liquid Chromatography-Tandem Mass Spectrometry Techniques
}

\author{
Slim Smaoui $\mathbb{D}^{1},{ }^{1}$ Olfa Ben Braïk $\left(\mathbb{D},^{2}\right.$ and Hajer Ben Hlima $\mathbb{D}^{3}$ \\ ${ }^{1}$ Laboratory of Microbial, Enzymatic Biotechnology and Biomolecules (LBMEB), Center of Biotechnology of Sfax, \\ Road of Sidi Mansour Km 6, P.O. Box 1177, 3018, University of Sfax, Sfax, Tunisia \\ ${ }^{2}$ Laboratory of Transmissible Diseases and Biologically Active Substances (LR99ES27), Faculty of Pharmacy, 5000, \\ University of Monastir, Monastir, Tunisia \\ ${ }^{3}$ Algae Biotechnology Unit, Biological Engineering Department, National School of Engineers of Sfax, 3038, University of Sfax, \\ Sfax, Tunisia \\ Correspondence should be addressed to Slim Smaoui; slim.smaoui@cbs.rnrt.tn
}

Received 14 September 2020; Revised 14 November 2020; Accepted 18 November 2020; Published 10 December 2020

Academic Editor: giorgia liguori

Copyright (C) 2020 Slim Smaoui et al. This is an open access article distributed under the Creative Commons Attribution License, which permits unrestricted use, distribution, and reproduction in any medium, provided the original work is properly cited.

In the entire world, cereals and related foodstuffs are used as an important source of energy, minerals, and vitamins. Nevertheless, their contamination with mycotoxins kept special attention due to harmful effects on human health. The present paper was conducted to evaluate published studies regarding the identification and characterization of mycotoxins in cereals and related foodstuffs by liquid chromatography coupled to (tandem) mass spectrometry (LC-MS/MS) techniques. For sample preparation, published studies based on the development of extraction and clean-up strategies including solid-phase extraction, solid-liquid extraction, and immunoaffinity columns, as well as on methods based on minimum clean-up (quick, easy, cheap, effective, rugged, and safe (QuEChERS)) technology, are examined. LC-MS/MS has become the golden method for the simultaneous multimycotoxin analysis, with different sample preparation approaches, due to the range of different physicochemical properties of these toxic products. Therefore, this new strategy can be an alternative for fast, simple, and accurate determination of multiclass mycotoxins in complex cereal samples.

\section{Introduction}

Most people of developed and developing countries use cereals and cereal-based products as their primary source of nutrients and energy [1-4]. Nevertheless, due to rich contents of fat, protein, and minerals, they are providing a great environment for fungal growth $[5,6]$. Contamination of cereals in preharvest and postharvest stages with fungi can lead to the production of mycotoxins [7-9]. In this line, some environmental agents such as humidity, temperature, inadequate storage conditions, insect damage, and drought play important roles in the level and diversity of contamination by mycotoxins [10-12]. In addition, the incidence and mycotoxins concentration in cereal-based food products can be associated with some factors, such as physical and chemical food characterization ( $\mathrm{pH}$, composition, and water activity), production management (storage, harvesting, and conditions of processing), and weather status (humidity and temperature) [13-16].

These secondary toxic metabolites are secreted by some important fungal genera including Aspergillus, Penicillium, Fusarium, and Alternaria [17-22]. Naturally toxic compounds with a low molecular weight and a high bioaccumulation ability, mycotoxins, are thermally stable $[23,24]$. According to literature, among more than 400 identified secondary compounds, deoxynivalenol (DON), ochratoxin A (OTA), zearalenone (ZEN), and aflatoxins (AFTs) were renowned as the most studied mycotoxins and are considered a hazard to human or animal health [25-32].

Currently, biologically modified mycotoxins, introduced due to plant metabolism and known as "masked mycotoxins," have also been described such as ZEA-14-sulfate (Z4S) and $\alpha$ - and $\beta$-zearalenol ( $\alpha$ - and $\beta$-ZOL) [33-37]. The most common examples are 3-acetyl-deoxynivalenol (3- 
ADON) and 15-acetyl-deoxynivalenol (15- ADON) which have been detected in Fusarium-contaminated cereals [38-41]. Both compounds ascend from 3,15-diacetyl deoxynivalenol $[42,43]$. The occurrence of 3-ADON and 15ADON in cereals has been described in some studies [44-47].

For the determination of mycotoxins in cereals and related foodstuffs, sampling of nonhomogeneous compounds and the analytical techniques are strongly important. In this line, proper sampling techniques must be put in place to obtain representative results. Therefore, sample selection, sample size, and number of incremental samples must be well recognized due to the mycotoxin heterogeneous distribution within the lots $[48,49]$. Since fungal growth is limited to certain locations in the lot and arbitrarily distributed, fungi contamination and mycotoxin production are considered as "spot processes" [48]. According to the Commission Regulation (EC) No. 519/2014 [50], from lots $\geq 50$ tonnes, incremental sample number must be a minimum of 100 , with a total of $10 \mathrm{~kg}$ of aggregate samples. For lots $<50$ tonnes, 3 to 100 incremental samples should be collected, with a corresponding aggregate sample weight of 1 (minimum weight) to $10 \mathrm{~kg}$. In the case of lots $>500$ tonnes, the representative sample should be at least $10 \%$ of the lot.

Analysis of mycotoxin in cereals and related foodstuffs is a decisive practice to approve food security. Several detection methods have been established, among the most common currently used are LC-MS/MS methods. When compared to other separation and detection techniques, LCMS/MS methods present very high analytical sensitivity. Extraction procedures and suitable clean-up, providing good recoveries and reducing matrix effects, are consequently extremely important to analytical method development and optimization. In this way, aqueous solvents and/or acidic solvents are crucial for quantitative extraction of FBs or OTA, while high organic solvents are suitable for mycotoxins such as AFs, OTA, and ZEA [51-53]. On the other hand, clean-up procedures towards mycotoxin analyses are largely performed by solid-phase extraction (SPE) or immunoaffinity columns (IAC) $[54,55]$. Based on solid samples such as cereals and related foodstuff samples, SPE was used as a clean-up and/or concentration step following a prior extraction procedure $[56,57]$. Several SPE columns are commercially available, with different solid phases ranging from C18 materials (ion exchange) to more specific adsorbent materials $[56,58,59]$. IAC, a method based on the interaction between antigen and antibody, displays some advantages, including a minimal loss of mycotoxins and a maximal elimination of interfering substances [60-62]. Compared to SPE extraction, the utilization of IAC as a clean-up procedure could greatly improve the specificity of subsequent analysis [54]. Other comparable clean-up procedure includes the QuEChERS-like method, which offers the opportunity to extend the number of analytes to be analyzed by a less time-consuming approach [58, 63]. According to Amirahmadi et al. [64], this method involves extraction with acetonitrile and partitioning clean-up after the addition of a salt mixture $\left(\mathrm{MgSO}_{4}\right.$ and $\left.\mathrm{NaCl}\right)$. Remarkably, QuEChERS is reliable with a number of advantages, such as simplicity, minimum steps, and effectiveness in cleaning-up complex samples [65].

For quantitative analysis of mycotoxin in cereal-based food samples, chromatographic techniques showed a group of techniques most commonly used which are highly selective, sensitive, and accurate [66-69]. For mycotoxin analysis, high-performance liquid chromatography (HPLC), thin-layer chromatography (TLC), gas chromatography (GC), and LC-MS/MS are commonly used chromatographic techniques [70, 71]. HPLC-UV, HPLC-diode array (DAD), HPLC-fluorescence detector (FLD), or mass spectrometry (MS) detector has been used to detect AFT, OTA, DON, ZEN, fumonisins (FUM), citrinin (CIT), and patulin (PAT). By using Liquid chromatography techniques to mass spectrometry (LC-MS/MS), the concurrent detection of multiple mycotoxins in various cereals and related foodstuffs products was established [70, 71]. TLC is cost-effective, simple, and suitable for rapid screening of common mycotoxin, but the lack of automation limits its use; moreover, GC coupled with electron capture (ECD), flame ionization (FID), or MS detector applied for volatile mycotoxins (trichothecenes (TCTs) and PAT) also limits its commercial use $[72,73]$.

Consecutively, the present review presents an emphasized overview on the development, optimization, and validation of LC-MS/MS-based methodologies towards the analysis of mycotoxins in cereals and related products. In addition, clean-up and extraction procedures and chromatographic and detection parameters, as well as the analytical method performance process, were well discussed.

\section{Analytical Methods: Liquid Chromatography-Tandem Mass Spectrometry (LC-MS/MS)}

The basic principle of MS/MS is the selection and fragmentation of precursor ion and measurement of the $\mathrm{m} / \mathrm{z}$ ratio of the product ions formed [73, 74]. There are two fundamentally different approaches to MS/MS: tandem mass spectrometry in space or in time [75]. The triple quadrupole $(\mathrm{QqQ})$ was the frequently used space instrument tandem mass spectrometry in space. Equally, other examples of tandem mass spectrometers included quadrupole-time-of-flight (QqToF) and Orbitrap hybrid instruments [76-79]. However, tandem-in-time instruments are typically ion-trapping mass spectrometers, which comprise 3D quadrupole ion traps (QIT) [80], linear ion traps (LIT) [81, 82], and Fourier transform-ion cyclotron resonance (FT-ICR) instruments $[83,84]$.

After extraction with acetonitrile/water, QqQ LC-MS/ MS methods were examined for the quantification of TCTs and ZEA in cereals by using electrospray ionization (ESI) [85] and atmospheric pressure chemical ionization (APCI) $[86,87]$ interfaces.

Cavaliere et al. [88] presented their method for the determination of 8 TCTs, three FUM, ZEA, and alphazearalenol in corn samples and used ESI QqQ MS in both polarity modes. A positive-ion mode ESI QqQ LC-MS/MS 
method for the simultaneous determination of 16 mycotoxins on a cellulose filter was developed by Delmulle et al. [89].

In targeted mycotoxin determination LC-MS/MS, analytical methods using a QqQ and linear ion trap (QLIT) mass spectrometer are the most commonly used procedures [90]. The combination of QqQ MS (QqQ/QLIT) is valuable because this instrument retains the selective reaction monitoring mode (SRM) [75, 91, 92]. Rapid multimethods based on QqQ/QLIT approaches are able to analyze simultaneously up to 300 mycotoxins and also their metabolites or other related food contaminants depending on the length of the chromatographic run [92-95].

The sustained development of mass spectrometers, including Orbitrap-based systems as well as other instrument platforms such as the QTOF, was thus driven by aims of accelerating scan speed and increasing sensitivity $[96,97]$. This instrument can be defined as a triple quadrupole where the last quadrupole is substituted by an oa-TOF or as the addition of a collision cell to a TOF analyser and a quadrupole analyser [97]. To perform fragmentation with higher-energy collisional dissociation (HCD), a gas-filled quadrupole (the HCD cell) was fitted directly after the C-trap [98]. Besides, it has been stated that TOF and Orbitrap analyzers, with resolving power of $10,000-100,000$ and 140,000-240,000 (full width at half maximum defined at $\mathrm{m} / z$ ), were used respectively [75]. These analyzers are very sensitive making easier the analytes identification giving accurate results even when we are dealing with very low levels of analytes. Some authors have exploited their potential in the quantitative analysis of mycotoxins showing higher significance for Orbitrap [99].

A new generation of hybrid techniques such as the Q-orbital ion trap ( $\mathrm{Q}$ Exactive) instrument combines the advantages of high-performance quadrupole selection of precursor ions with those of high-resolution mass detection $[100,101]$. The subsequently developed Q Exactive instrument allowed precursor ion isolation on an exactive-type mass spectrometer. For isolation of precursors, a mass filtering quadrupole was utilized [101, 102]. Thereafter, for detection, the HCD cell voltages are ramped and ions are conveyed back into the C-trap from where they are injected into the Orbitrap. In fact, structural information can be obtained on compounds of interest and fragment ions can be used for confirmation in targeted analyses [102].

Regarding identification, metabolite ions in a full scan spectrum (MS) are subsequently isolated to generate MS/MS spectra; data-dependent acquisition (DDA) approach is the most common strategy $[103,104]$. Thereafter, metabolite structure is elucidated through MS/MS spectral similarity corresponding to the standard metabolite spectral library. In this context, Human Metabolome Database (HMDB) [105], METLIN [106], and MassBank [107] are frequently referred to as a spectrum-centric approach. MassBank is the first public source of mass spectra of small chemical compounds for life sciences $(<3000 \mathrm{Da})$ [107], while METLIN includes an annotated list of known metabolite structural information that is easily cross-correlated with its catalogue of highresolution Fourier transform mass spectrometry (FTMS) spectra, MS/MS spectra, and LC/MS data [106]. Application of DDA in analysis of mycotoxins was demonstrated in several recent studies $[108,109]$. Nevertheless, DDA suffers from numerous limitations. For example, in one experiment, not a limited number of ions with highest abundance detected in the full MS scan are isolated and fragmented in a product ion scan experiment [110-112]. Also, the selected precursor ions may be derived from many adducted ions instead of molecular ions $[113,114]$. If applied to the analysis of mycotoxin-contaminated foodstuff, these problems would be aggravated since these metabolites habitually occur at lower concentrations, and absolute quantification is critical for compliance with regulatory limits [109].

Technological advances have greatly increased the resolution, speed, and sensitivity of mass spectrometers. This has allowed for new types of nontargeted methods to become more practicable, precisely data-independent acquisition (DIA). It should be noted that the DIA approach depends on the width of the isolation window, and many ions can be cofragmented. Consequently, the product ion spectra are more complex compared with targeted methods and at each segment producing one multiplexed MS/MS spectrum derived from multiple precursor ions $[115,116]$. DIA approaches have been established on each of the Orbitrap mass spectrometer platforms to take benefit of their specific architectures. Development in the area of DIA included methods such as wide isolation window SIM scan DIA (WiSIM-DIA) on the Orbitrap fusion mass spectrometer [117]. This approach utilized an ultrahigh-resolution SIM scan for quantification, complementary with classic DIA. In proteomics, several data MS analysis methods and programs, such as DIA-Umpire [118] and Skyline $[119,120]$, were used. In this line, DIA-Umpire, a comprehensive computational workflow and open-source software for DIA data, detects precursor and fragment chromatographic features and assembles them into pseudo-MS/MS spectra which can be identified using conventional database searching and protein inference tools without the need for a spectral library [119]. In the same way, Egertson et al. [120] described the use of DIA on a Q-Exactive mass spectrometer for the detection and quantification of peptides in complex mixtures using the Skyline Targeted Proteomics Environment.

The most promising feature of DIA analysis of mycotoxins is that the data generated is ideal for retrospective analysis. Newly characterized mycotoxins can be identified in archived data by high-resolution precursor mass, retention time, and multiple product ions. High-resolution MS alone has been used to collect data that can be retrospectively analyzed for the presence of mycotoxins [109, 120, 121]. In this vein, Renaud et al. [109] reported the development of a powerful LC-DIA analysis method on a Q Exactive hybrid quadrupole-Orbitrap mass spectrometer for mycotoxin analysis produced by Fusarium graminearum in maize. On the contrary, Berthiller et al. [122] reported a method detection limit of $0.012 \mathrm{~g} / \mathrm{ml}$ for D3G in purified sample extracts, corresponding to $0.02 \mathrm{~g} / \mathrm{g}$ in contaminated cereals. These authors also estimated their LOD from the signal 
intensity of their standards, based on the limited ion suppression they observed. The pigment LOQ and LOD were 4.3 and $0.0005 \mathrm{~g} / \mathrm{kg}$, respectively. Good linearity for the pigment standard curve $\left(\mathrm{R}^{2} 0.999\right)$ was also observed.

In LC-MS, the majority of multimycotoxin methods used ESI interface. In fact, positive-mode ESI is exclusively applied to couple high-performance liquid chromatography (HPLC) or ultrahigh-performance liquid chromatography (UHPLC) and MS detection [73, 123-126]. This technique has been effectively used for the synchronized quantification of mycotoxins with different chemical structures [54] in one single run $[89,126]$. The LC/MS-MS technique has been reported by many studies in multimycotoxin determination, such as 17 different mycotoxins in barley and malt [127].

\section{Current Methods Used for LC-MS/MS Determination of Mycotoxins in Cereals and Related Products}

The approaches include those used for screening and quantification in both official control and research. It should be noted that the approaches discussed mostly have been developed for the determination of EU-regulated mycotoxins in various food matrices to strictly respond to the EU legislation [128]. Despite the interesting benefits that could procure MS/MS as a very selective technique, its signal could be overestimated and lost in the case of some challenging samples leading finally to false positive results. Also, although LC-MS is considered to be a highly sensitive analytical technique, trace detection levels of some analytes seem impossible especially when compromises related to sample preparation and LC-MS/MS conditions have to be made. These methods are developed based on the QuEChERS approach [129]. This approach was established for a very rapid extraction and purification with regard to multipesticide analysis. Its relevant principle relies on the partitioning of an acetonitrile-water mixture induced by addition of inorganic salts. In general, LC-MS/MS techniques including QuEChERS approach are ineffective for the AFs and OTA detection in baby foods at the EU limits. Therefore, for these particular metabolites, specific clean-up methods with immunoaffinity columns (IACs) or combinations with another clean-up technique are used [52]. The application of immunoanalysis for a rapid screening of mycotoxins represents an attractive analytical method commonly used nowadays. The main criteria for research of such approaches include simplification and rapidity of analysis, sensitivity improvement, and matrix effect reduction. Immunoassays generally applied for rapid detection of individual mycotoxins are summarized in a review concerning immunochemical assays [52]. The common immunomethods applied for mycotoxin detection rely on binding of specific antibodies to a solid support (direct competitive ELISA format) or coated antigens (indirect competitive ELISA format). These formats are used in all nonhomogenic methods: microtiter plate immunoassays and sensors. Homorganic methods implicate the fluorescent polarization and capillary electrophoretic immunoassays [52].
Lattanzio et al. [52] detected and quantified aflatoxins $\left(B_{1}, B_{2}, G_{1}\right.$, and $\left.G_{2}\right)$, ochratoxin $A$, fumonisins $\left(B_{1}, B_{2}\right)$, deoxynivalenol, zearalenone, T-2, and HT-2 toxins in maize. In fact, reversed-phase liquid chromatography coupled with electrospray ionization triple quadrupole mass spectrometry (LC/ESI-MS/MS) was used as chromatographic mobile phase, a linear gradient of methanol/water containing $0.5 \%$ acetic acid and $1 \mathrm{mM}$ ammonium acetate. The method exhibited good linearity; also, matrix-coordinated calibration curves for all analytes were linear over the relevant working range with $r$ (coefficient of correlation) values between 0.9980 and 0.9999 [52]. In addition, recoveries higher than $79 \%$ were obtained for all tested mycotoxins with relative standard deviations less than $13 \%$. These authors reported that method performances were quite satisfactory for all tested mycotoxins at contamination levels close to or below the relevant EU maximum permitted or recommended levels. Limits of detection (LOD) in maize ranged from 0.3 to $4.2 \mu \mathrm{g} / \mathrm{kg}$ [52]. These LODs are similar with or slightly lower than those reported by other authors using MRM detection for the analyses of the same mycotoxins in maize or maize-based food extracts after SPE cleanup $[86,88,89]$.

On the other hand, QuEChERS procedure has been used for the development of an LC-MS/MS assay for the determination of 17 mycotoxins in cereals for human consumption and infant cereals [129]. All tested matrices gave LOQs below the maximum levels except for AFLA B1 in infant cereals (maximum level $=0.1 \mu \mathrm{g} / \mathrm{kg}, \mathrm{LOQ}=1 \mu \mathrm{g} / \mathrm{kg}$ ). Matrix effects were nevertheless more important in soya (LOQ for the aflatoxins $B_{1}, B_{2}, G_{1}$, and $G_{2}=2 \mu \mathrm{g} / \mathrm{kg}$ ) and even more in corn gluten (pet food material). Higher LOQs were thus obtained in corn gluten (pet food ingredient) for which no regulatory limits have been established [130]. These authors, also, have chosen the $\mathrm{ESI}^{+}$mode since the sensitivity of critical compounds with low maximum levels (i.e., aflatoxins $B_{1}, B_{2}, G_{1}$, and $G_{2}$ and OTA) was visibly enhanced. In contrast, an acceptable sensitivity for $\mathrm{ZON}$, as $[\mathrm{M}-\mathrm{H}]^{-}$ion, was only obtained in the ESI-mode. At the same time, the addition of ammonium formate to the aqueous mobile phase clearly enhanced the sensitivity for both type A and B TCTs detected under their ammonium adduct $\left[\mathrm{M}+\mathrm{NH}_{4}\right]^{+}$, whereas formic acid in both mobile phases increased the overall sensitivity, giving better peak shape for the acidic compounds, i.e., FB1, FB2, and OTA [131].

Modified QuEChERS which used acidified acetonitrile (ACN), $\mathrm{MgSO}_{4}, \mathrm{NaCl}$, and citrate buffer salts, combined with dispersive solid-phase extraction (d-SPE) clean-up and followed by LC-ESI-MS/MS method, was applied for the determination of EU-regulated mycotoxins in several cereals such as wheat, maize, and rice [132]. In cereals, aflatoxins, ochratoxins, fumonisins, trichothecenes, and zearalenone were detected and quantified. The performance of the method was assessed and compared to European Commission (EC) Regulations, by studying the selectivity, specificity, LOD, LOQ, linear dynamic range (LDR), matrix effect, accuracy, precision, and uncertainty. In this context, Fernandes et al. [132] reported a good linearity $\left(r^{2}>0.9713\right)$ 
for all mycotoxins investigated, and LODs $(S / N=3)$ and LOQs $(S / N=10)$ were below the tolerance levels of mycotoxins set by EC. Recoveries of the extraction process, obtained with different spiked concentrations, ranged from 72.9 to $120.6 \%$, with relative standard deviations (RSD) lower than $23.0 \%$.

Rubert et al. [133] reported the comparison of four different extraction techniques used in the determination of 32 mycotoxins in barley. These methods included QuEChERS modification, matrix solid-phase dispersion (MSPD: extraction $\mathrm{MeCN} / \mathrm{MeOH}, 50 / 50, \mathrm{v} / \mathrm{v}$ ), supported liquid extraction (SLE: extraction $\mathrm{MeCN} /$ water/acetic acid, $79 / 20 / 1, \mathrm{v} / \mathrm{v} / \mathrm{v}$ ), and solid-phase extraction (SPE, previous SLE extract). Accordingly, it has been shown that modified QuEChERS method was faster and easier than the other methods. Also, it enables to extract well all of the mycotoxins (from $64.1 \%$ DON-3-G to $93.4 \% \mathrm{~T}-2$ ). These authors validated the method according to the directive and guide on that subject [134]. In this regard, confirmation of identity, specificity/selectivity, linearity, lowest calibration level (LCL), ranging between 1 and $100 \mu \mathrm{g} / \mathrm{kg}$ for enniatin B (ENB) and NIV, respectively was done. The precision, process efficiency, and recovery were, also, studied [135]. Remarkably, Rubert et al. [133] reported that the UHPLCHRMS was a robust technique for validation and routine mycotoxin analysis. This latter technique showed sensitivity and selectivity to identify simultaneously 32 mycotoxins.

Rubert et al. [135] developed a method to analyze simultaneously 14 mycotoxins (nivalenol (NIV), deoxynivalenol (DON), aflatoxin $\mathrm{B}_{1}\left(\mathrm{AFB}_{1}\right)$, aflatoxin $\mathrm{B}_{1}\left(\mathrm{AFB}_{2}\right)$, aflatoxin $\mathrm{G}_{1}\left(\mathrm{AFG}_{1}\right)$, aflatoxin $\left(\mathrm{AFG}_{2}\right)$, diacetoxyscirpenol (DAS), fumonisin $\mathrm{B}_{1}\left(\mathrm{FB}_{1}\right)$, fumonisin $\mathrm{B}_{2}\left(\mathrm{FB}_{2}\right)$, ochratoxin A (OTA), HT-2, T-2, ZEN, and beauvericin (BEA)) by LCMS/MS. In this study, a comparison between eight sorbents (C18, C8, phenyl, amine-bonded phases, celite, silica, Florisil ${ }^{\circledR}$, and alumina (acidic, neutral, and basic)) using an optimized solvent, $\mathrm{MeCN} / \mathrm{MeOH}(50 / 50, \mathrm{v} / \mathrm{v}) 1 \mathrm{mM}$ ammonium, to elute the desirable compounds, was performed. As a result, FMs were only extracted with $\mathrm{C} 18$ or $\mathrm{C} 8$, being the best recoveries for all mycotoxins obtained with $\mathrm{C} 18$ (from $72 \%$ of ZEN to $93 \%$ of deoxynivalenol (DON)) [135]. The sensitivity was evaluated by LOD and LOQ values and then was calculated analysing fortified flour sample. In all these cases, LOQs were always lower than the European maximum levels (MLs) established by EU. The authors commented that the precision, calculated as RSD, was between $3 \%$ and $14 \%$ for the intraday test and from $4 \%$ to $14 \%$ for the interday test. The recovery ranges in low and high spiked levels were $68.8-89.6 \%$ and $72.6-87.5 \%$, respectively, for the intraday test and $68.7-88 \%$ and $72.8-87.6 \%$ for the interday test at LOQ and 10 times LOQ, respectively. Similar to matrix effects, recoveries and its repeatability were studied in the three varieties of cereal (wheat, corn, and rice) flour by three replicates. In all matrix tested, recoveries were satisfactory (between $70 \%$ and $120 \%$ ).

Serrano et al. [136] studied the contents of 14 mycotoxins in samples of different cereal (rice, wheat, maize, rye, barley, oat, spelt, and sorghum) and cereal products (snacks, pasta, soup, biscuits, and flour) from four countries of the
Mediterranean region (Spain, Italy, Morocco, and Tunisia). Samples were extracted with matrix solid-phase dispersion (MSPD) and determined by liquid chromatography-tandem mass spectrometry with a triple quadrupole mass analyser. The frequency of contaminated samples from Spain, Italy, Tunisia, and Morocco was 33\%, 52\%, 96\%, and 50\%, respectively. For legislated mycotoxins (AFs, FBs, DON, ZEN, and OTA), the LOQs were lower than the MLs established by the European Union (EC 401/2006) [137]. For fumonisins (FBs), the levels ranged from $<\mathrm{LOQ}-184 \mu \mathrm{g} / \mathrm{kg}$ for $\mathrm{FB}_{1}$, and from 121 to $176 \mu \mathrm{g} / \mathrm{kg}$ for $\mathrm{FB}_{2}$. The maximum $\mathrm{FB}_{1}$ value $(184 \mu \mathrm{g} / \mathrm{kg})$ was found in a wheat pasta sample from Tunisia, and the maximum $\mathrm{FB}_{2}$ value $(176 \mu \mathrm{g} / \mathrm{kg})$ was found in a rice grain sample from Morocco. These results were lower than those obtained in other studies for maize, wheat, rice, and barley products [138-140]. Recoveries of fortified cereal samples at two spiked levels ranged between $68.7-89.6 \%$ and 72.6-87.6\%; in addition, the relative standard deviations varied from $3 \%$ to $14 \%$. These values agree with EU criteria [141]. In addition, all mycotoxins exhibited good linearity over the working range (low concentration level at LOQ), and the regression coefficient of calibration curves was higher than 0.992 [136].

Otherwise, Lacina et al. [142] have performed different extraction methods for the simultaneous analysis of 288 pesticides and 38 mycotoxins. In fact, three different extractions were carried out for wheat and other products: aqueous acetonitrile extraction followed by a modified QuEChERS method (method A), aqueous acetonitrile extraction (method B), and pure acetonitrile extraction (method C). In these extraction procedures, different eluent modifiers were used for positive- and negative-mode ESI measurements to obtain high sensitivity and very sharp peaks. Then, it has been found that pure acetonitrile extraction (method C) did not show acceptable recoveries compared to QuEChERS approach and aqueous methanol extraction that present satisfactory recoveries ranging from $70 \%$ to $120 \%$ with RSD less than $20 \%$ for most of the analyte-matrix combinations. Despite the fact that QuEChERS-like method led to lower LOQ and more coherent results, the recoveries were low especially for polar analytes (DON 3-glucoside (DON-3-Glc), NIV, T2 tetraol) due to the partitioning step. On the other hand, extraction using QuEChERS approach was selected as the most suitable procedure for the tested analytes [142].

Juan et al. [143] tested several solvent mixtures: $\mathrm{MeCN} /$ $\mathrm{MeOH}(60 / 40, \mathrm{v} / \mathrm{v}), \mathrm{MeCN} / \mathrm{MeOH}(40 / 60, \mathrm{v} / \mathrm{v}), \mathrm{MeCN} /$ water $(84 / 16, \mathrm{v} / \mathrm{v})$, and $\mathrm{MeCN} /$ water $(16 / 84, \mathrm{v} / \mathrm{v})$ to extract TRC and ZEN from grain cereal, flour, and bread. It has been found that the highest recoveries and the lowest matrix effects were shown with the $\mathrm{MeCN} /$ water $(84 / 16, \mathrm{v} / \mathrm{v}$ ) mixture. Analytes were determined by LC-MS/MS and relative recoveries obtained were higher than $70 \%$. In this line, the obtained recoveries ranged for wheat were $73-98 \%$; oat, 75-96\%; barley, 73-99\%; and spelt, 78-99\%. In addition, the precision (RSDs) of theses samples ranged for wheat was 2.4-11; oat, 2.8-13; barley, 2.8-15; and spelt, 2.4-12. As well, a good linearity $\left(r^{2}>0.992\right)$ was obtained and quantification limits $(2.5-25 \mathrm{ng} / \mathrm{g})$ were below European Regulatory levels. 
Equally, sensitivity was high due to the low LOD and LOQ [143].

By using gradient RP-LC with atmospheric pressure chemical ionization triple quadrupole mass spectrometry (LC-APCI-MS/MS), Berthiller et al. [86] developed a novel method for the simultaneous determination of the Fusarium mycotoxins. Nivalenol, deoxynivalenol, fusarenon-X, 3acetyl-deoxynivalenol, the sum of 3-acetyl-deoxynivalenol and 15-acetyl-deoxynivalenol, diacetoxyscirpenol, HT-2 toxin, T-2 toxin, and zearalenone in maize have been detected [86]. The swift clean-up of maize samples was performed with MycoSep ${ }^{\circledR} \# 226$ columns, and the calibration curves for all analytes are linear over the working range of $30-1000 \mu \mathrm{g} / \mathrm{kg}$, respectively. Depending on the mycotoxin, squared correlation coefficients $\left(R^{2}\right)$ were in the range of $0.994-0.999$ and LOD ranged from 0.3 to $3.8 \mu \mathrm{g} / \mathrm{kg}$.

Barthel et al. [144] analyzed fifty nine samples of barley and barley products for 18 trichothecene mycotoxins by a sensitive LC-MS/MS. After sample extract clean-up on MycoSep ${ }^{\circledR}-226$ columns, these authors confirmed that LODs were ranged between $0.062-0.70 \mu \mathrm{g} / \mathrm{kg}$. Furthermore, the recovery was ranged between 75 and $104 \%$ for all mycotoxins with relative standard deviations (RSDs) between 2.1 and $17 \%$. The results complied with the requirements of Commission Regulation (EC) 401/2006 [145].

Ren et al. [146] developed an analytical method for the simultaneous quantification of 17 kinds of Aspergillus, Fusarium, and Penicillium mycotoxin contaminants in foods and feeds by ultrahigh-performance liquid chromatography combined with ESI triple quadrupole tandem mass spectrometry (UPLC-MS/MS) under the multiple reaction monitoring (MRM) mode and especially focused on the optimization of extraction, clean-up. The 10 positive ions and 7 negative ions of mycotoxins were separated by gradient elution with the retention time of 6.5 and $4 \mathrm{~min}$, respectively. The LOQ of selected analytes ranged from 0.01 to $0.70 \mu \mathrm{g} \cdot \mathrm{kg}^{-1}$, which was lower than the criteria of EU, USA, and other countries on the determination of the minimum limiting level of various mycotoxins in foods including baby foods and feed stuffs. In this way, Amézqueta et al. [147] determined the OTA residue in cocoa beans by HPLC with the LOQ value of $0.1 \mu \mathrm{g} \cdot \mathrm{kg}^{-1}$. Meanwhile, Sugita-Konsihi et al. [148] quantified the DON level using HPLC method and achieved reasonable LOQ value $\left(100 \mu \mathrm{g} \cdot \mathrm{kg}^{-1}\right)$. Papp et al. [149] validated an analytical method for the determination of AT $B_{1}, B_{2}, G_{1}$, and $G_{2}$ in corns, wheat, fish, peanut products, rice, and sunflower seeds by HPLC with the LOD range of $2-10 \mu \mathrm{g} \cdot \mathrm{kg}^{-1}$. Ren et al. [146], also, reported high correlation coefficients $\left(r^{2}>0.99\right)$ of 17 mycotoxins which were obtained within their respective linear ranges $\left(0.05-20 \mu \mathrm{g} \cdot \mathrm{kg}^{-1}\right.$ for 10 positive ions and $0.5-50 \mu \mathrm{g} \cdot \mathrm{kg}^{-1}$ for 7 negative ions) and reasonable recoveries (70.6-119.0\%) of them were also demonstrated in different spiked levels.

In 2012, Soleimany et al. [87] developed and used a LCMS/MS method for simultaneous determination of aflatoxins $\left(\mathrm{AFB}_{1}, \mathrm{AFB}_{2}, \mathrm{AFG}_{1}\right.$, and $\mathrm{AFG}_{2}$ ), ochratoxin $\mathrm{A}(\mathrm{OTA})$, zearalenone (ZEA), deoxynivalenol (DON), fumonisins $\left(\mathrm{FB}_{1}\right.$ and $\mathrm{FB}_{2}$ ), $\mathrm{T} 2$, and $\mathrm{HT} 2$-toxin in cereals. One-step extraction using solvent mixtures of acetonitrile : water : acetic acid (79:
$20: 1)$ without any clean-up was employed for extraction of these mycotoxins from cereals. The method exhibited good linearity over the relevant working range, and $R^{2}$ was between 0.950 for $\mathrm{DON}$ and 0.999 for $\mathrm{AFB}_{1}$. There was significant difference among the LODs in the standard solution and in matrices. LODs of mycotoxins standard solutions were far lower than LODs in matrixes. The LODs and LOQs of standards and matrixes ranged between $0.01-20 \mathrm{ng} / \mathrm{g}$ and $0.02-40 \mathrm{ng} / \mathrm{g}$, respectively, which are acceptable because they were far below the European Regulations for correspondent maximum levels of mycotoxins in foods. The LODs were lower than those reported by Sulyok et al. [53] and comparable to those reported by Ventura et al. [150]. Concerning recovery values, the study by Soleimany et al. [87] showed a range from $76.8 \%$ to $108.4 \%$ for all mycotoxins. The recovery results were better than those reported by Delmulle et al. [89] (52.6-89.2\%), Sulyok et al. [53] (75-108\%), Spanjer et al. [126] (46-115\%), and Monbaliu et al. [151] (76-105\%) for relevant mycotoxins. RSD\% for this procedure was lower than $12.7 \%$ for all mycotoxins.

In another study, von Bargen et al. [99] described the first application of isotopically labeled ${ }^{13} \mathrm{C}_{2}$-moniliformin for the analysis of moniliformin (MON) in cereals. The use of high-resolution mass spectrometry was described to be a suitable alternative technique for the detection of this compound. The developed method is based on the use of strong anion exchange columns for cleanup prior to HPLC analysis. In fact, the recovery rate was equal to $75.3 \%$, and the LOD and LOQ were 0.7 and $2.5 \mu \mathrm{g} / \mathrm{kg}$, respectively.

On the other hand, Sirhan et al. [152] established a new method based on QuEChERS followed by LC-ESI-QTOF$\mathrm{MS} / \mathrm{MS}$ to determine eight type-A and type- $\mathrm{B}$ trichothecenes in cereal samples. The recoveries of fortified cereal samples ranged from $61.9 \%$ to $110.9 \%$, and RSDs were lower than the acceptable $12 \%$ in all the cases. The sensitivity was determined by estimating the limit of detection (LOD) and limit of quantification (LOQ). Indeed, the LODs of type-A and type-B trichothecenes were 6.1-8.3 and $12.5-18.7 \mathrm{mg}=\mathrm{kg}$, respectively.

Habler and Rychlik [95] developed a multimycotoxin stable isotope dilution LC-MS/MS method for 14 fusarium toxins. Linearity, intraday precision, interday precision, and recoveries were $\geq 0.9982,1-6 \%, 5-12 \%$, and $79-117 \%$, respectively. Method accuracy was verified by analysing certified reference materials for deoxynivalenol, HT2-toxin, and $\mathrm{T} 2$-toxin with deviations below $7 \%$. The recoveries range between 86 and 109\% for all analytes with RSDs below 7\% and between 79 and $117 \%$ for the matrix calibration with maximal RSD of $17 \%$. The LODs range between 0.1 and $5 \mu \mathrm{g} /$ $\mathrm{kg}$ and the LOQs range between 0.2 and $15 \mu \mathrm{g} / \mathrm{kg}$, except for NIV and D3G, whose LODs and LOQs are 70 and $200 \mu \mathrm{g} / \mathrm{kg}$ and 10 and $30 \mu \mathrm{g} / \mathrm{kg}$, respectively. The high LOD and LOQ of NIV with 70 and $200 \mu \mathrm{g} / \mathrm{kg}$, respectively, are due to the low MS/MS sensitivity and are comparable with the limits reported by Ediage et al. [153]. The LODs and LOQs of the ENNs and BEA using the method presented here reveal 2-100 times higher sensitivity than those previously reported $[154,155]$. 


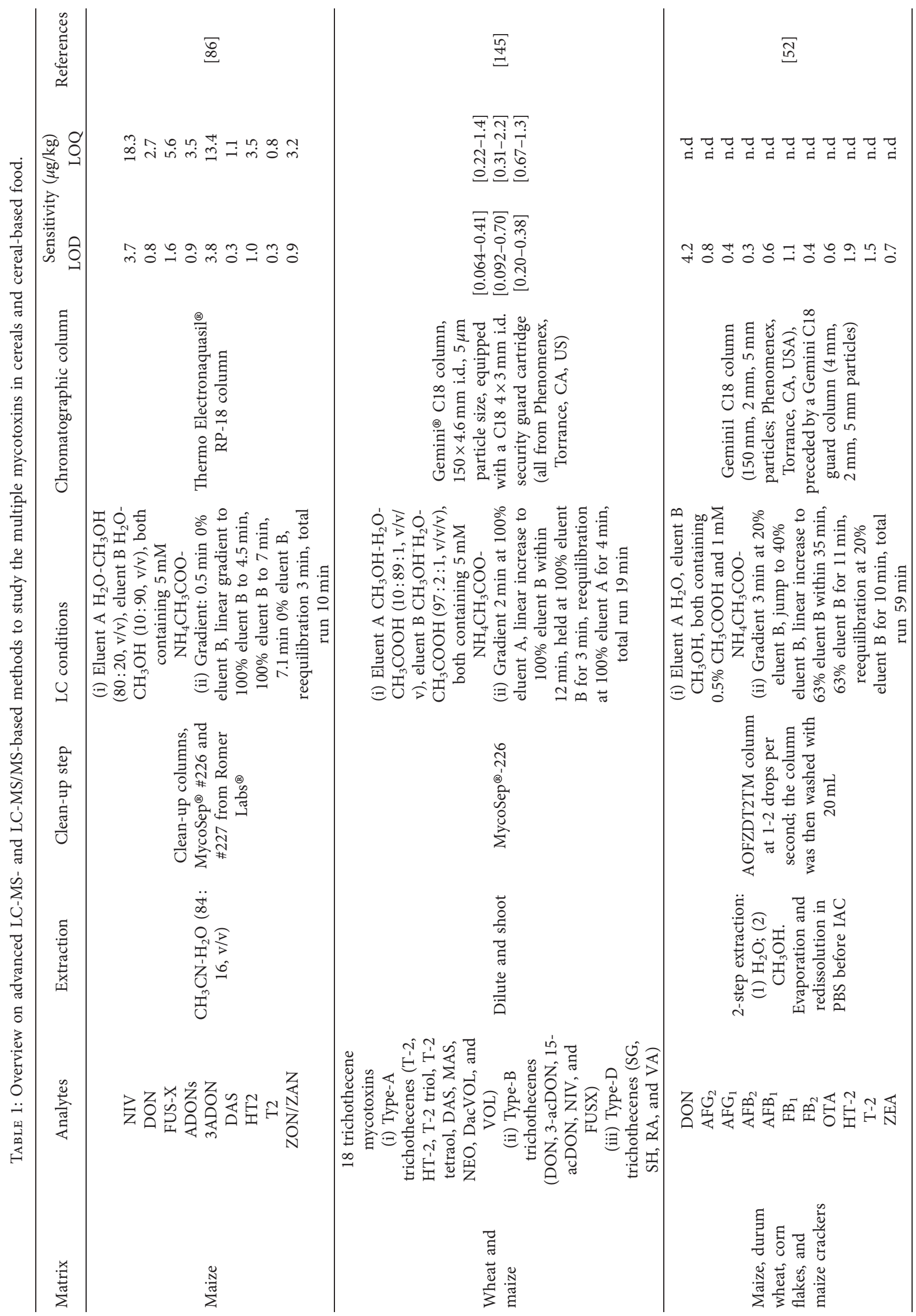




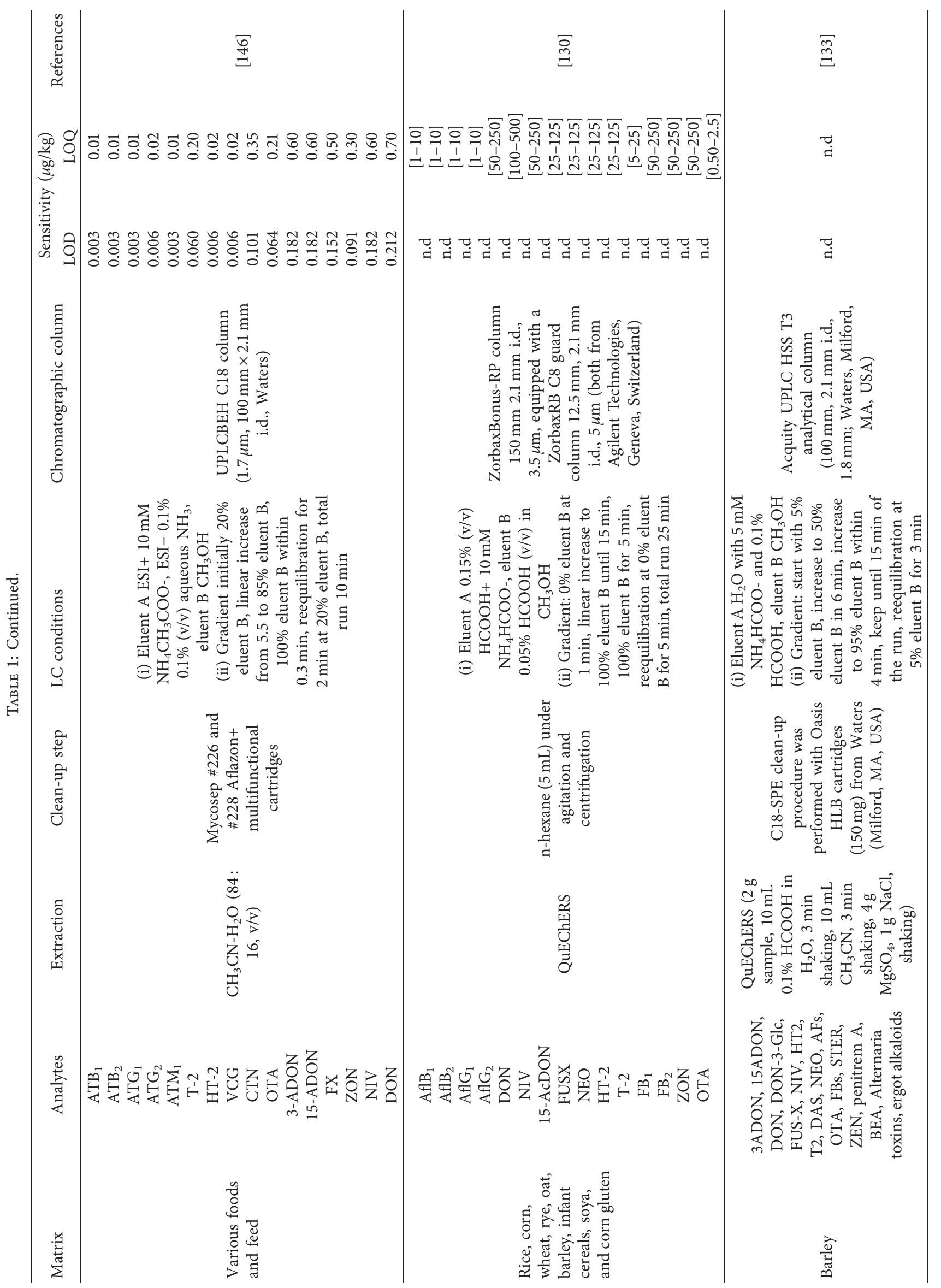




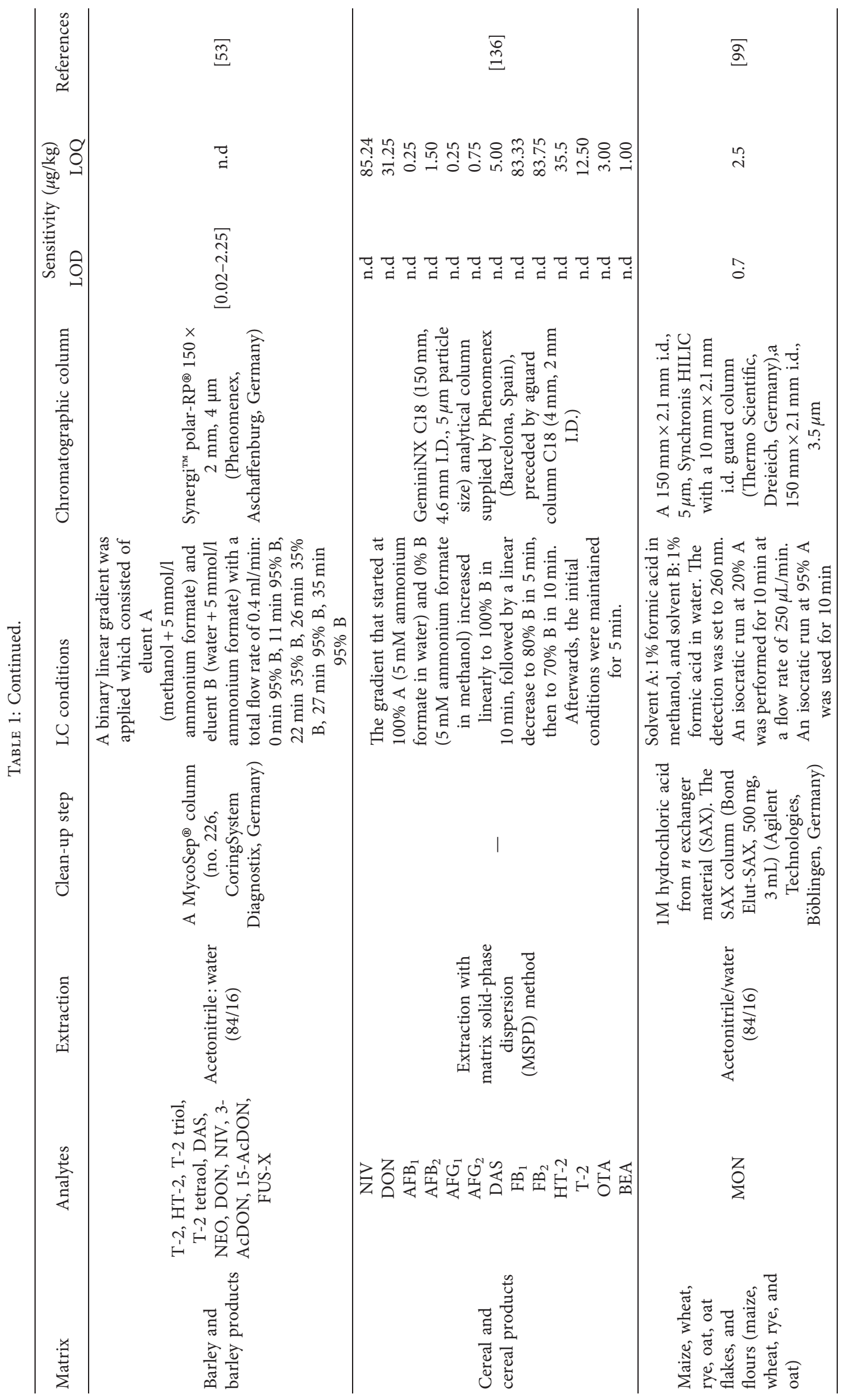




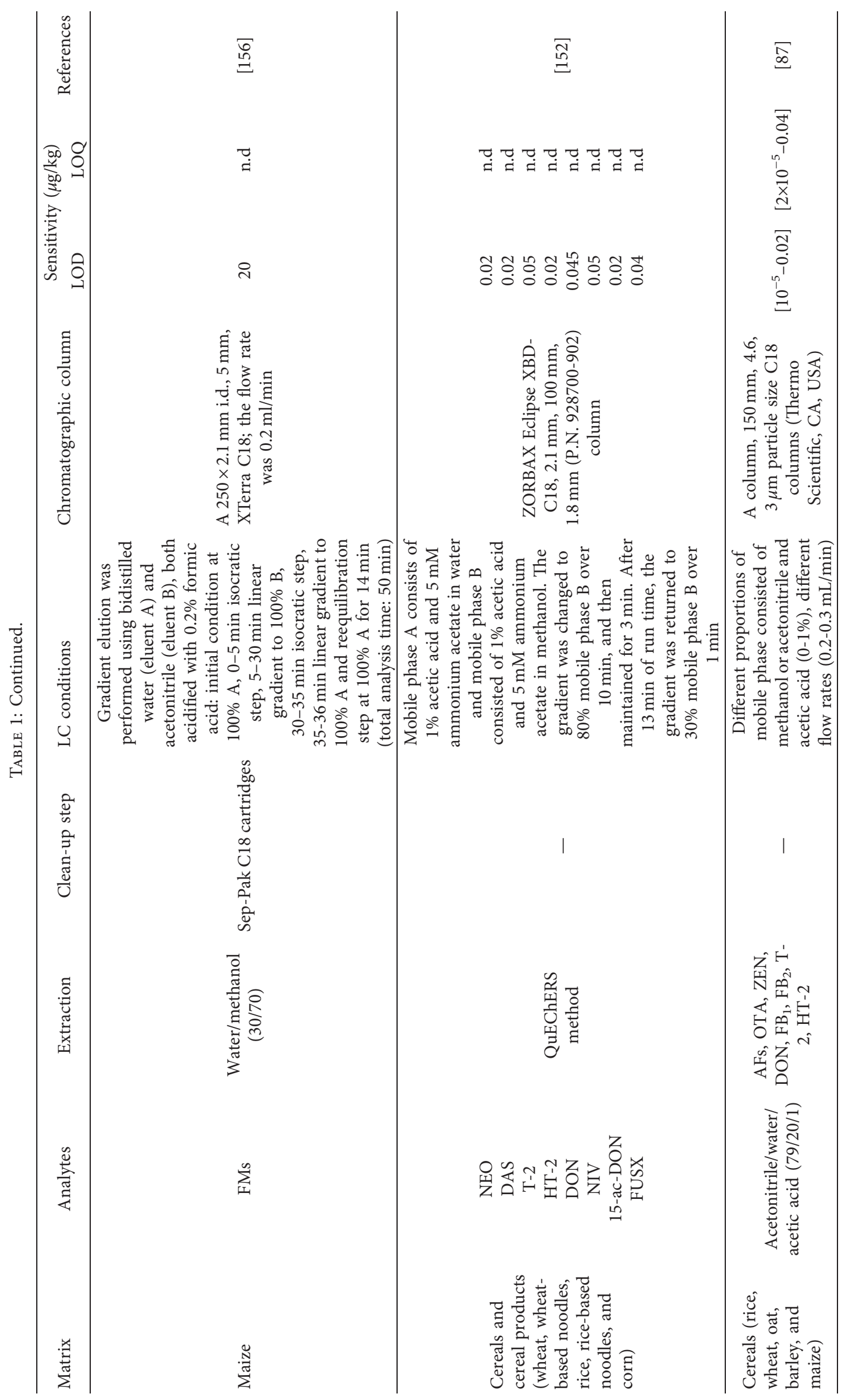




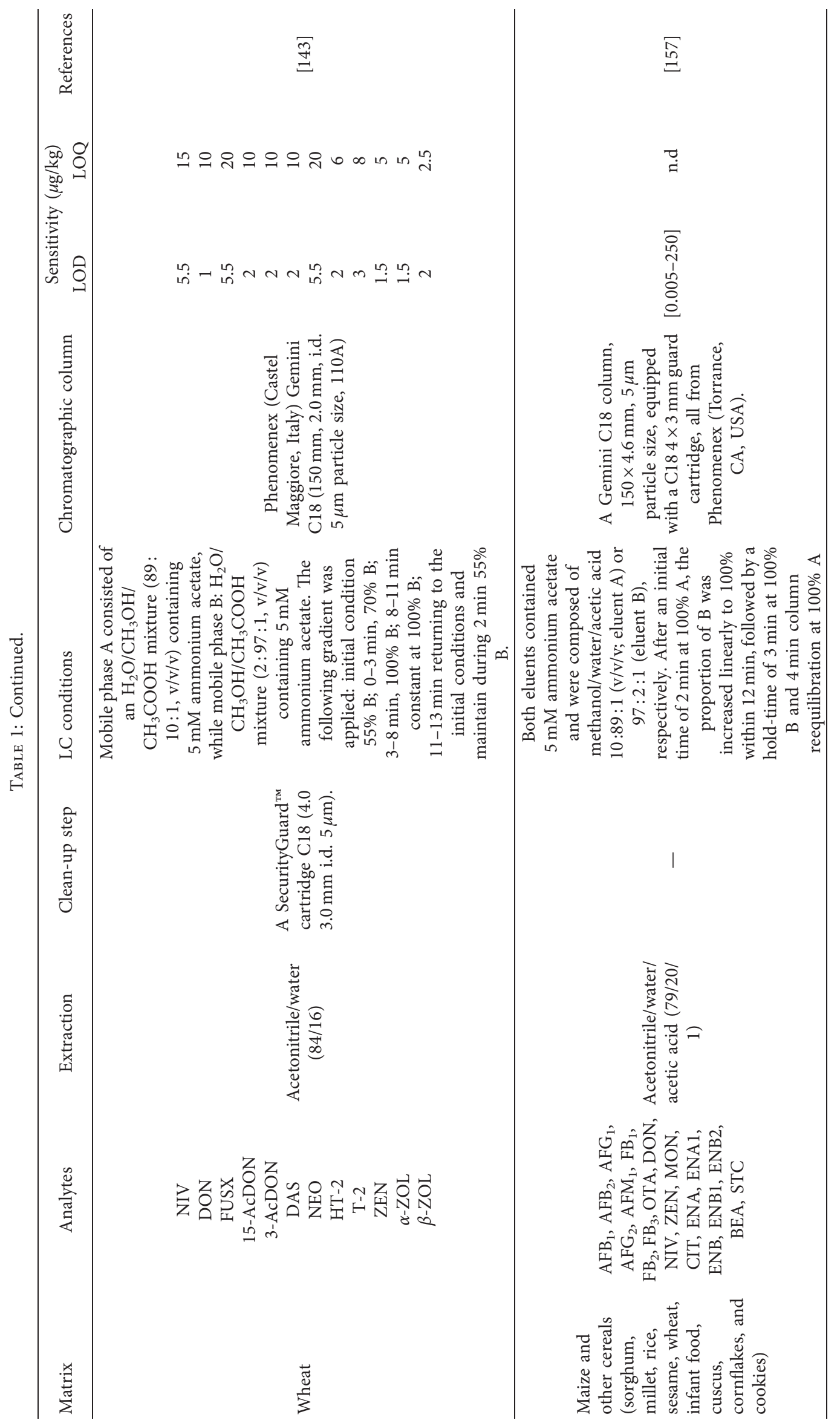




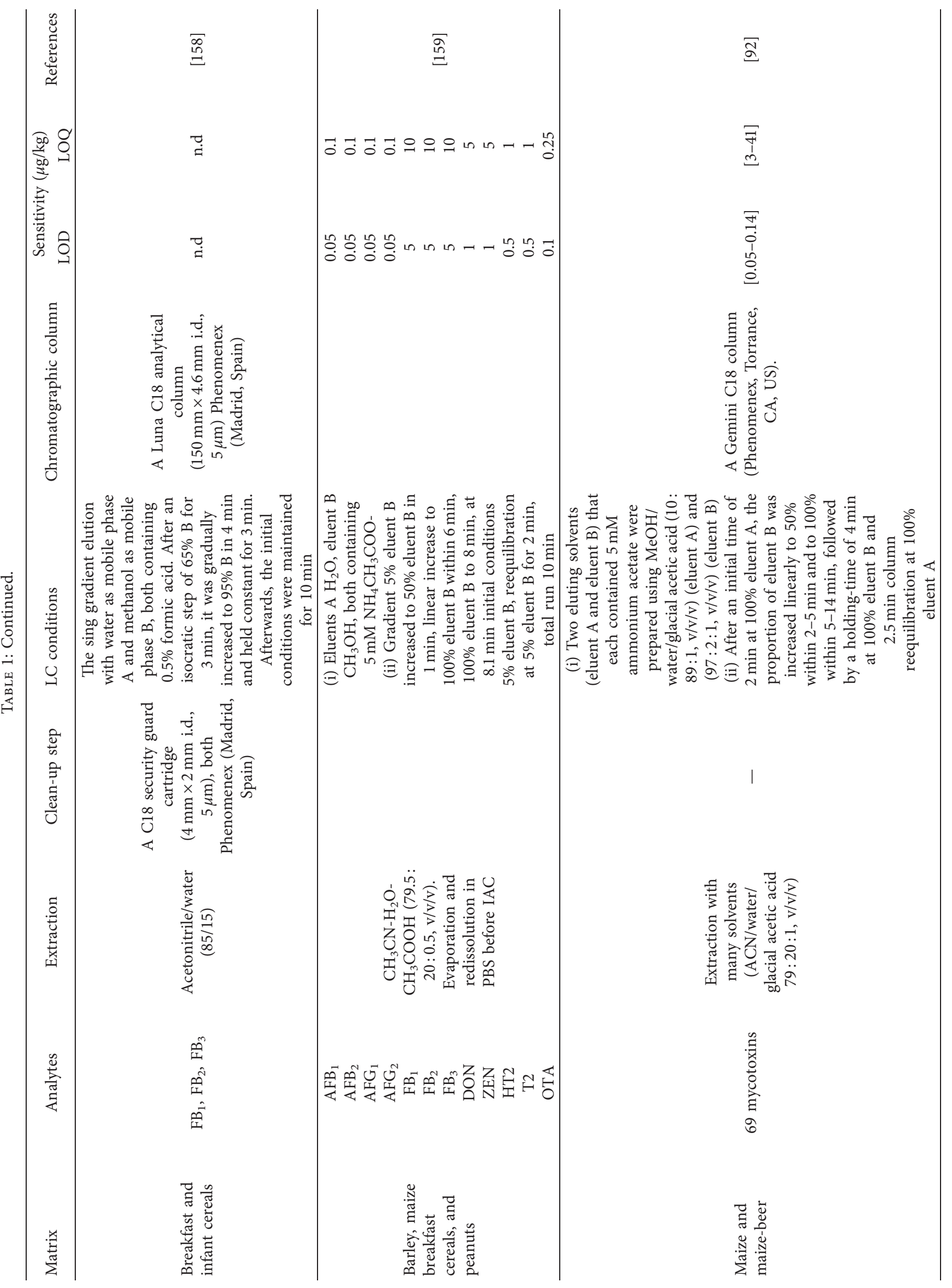




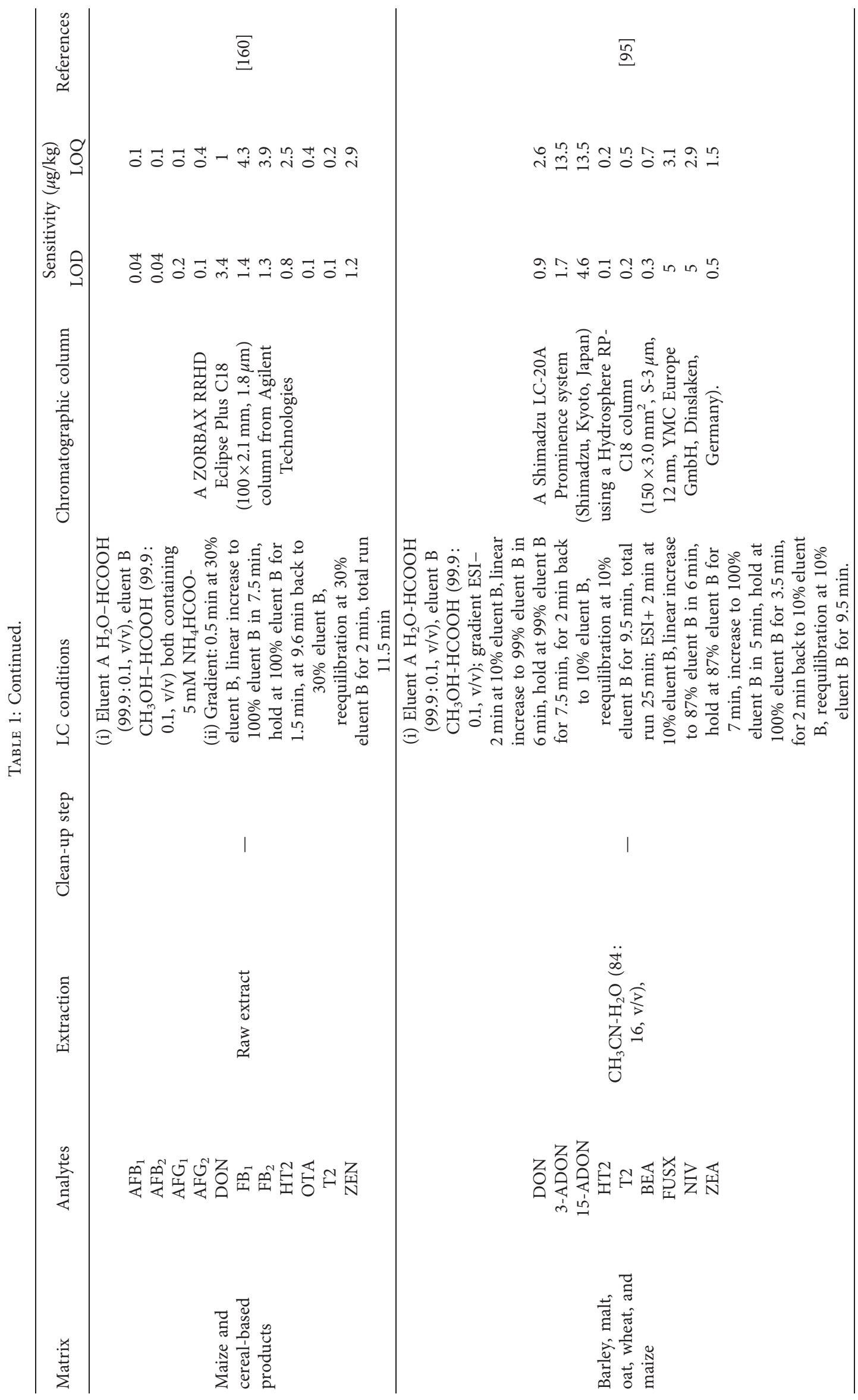


Some of the most common methods used for both mycotoxin identification and quantification are summarized in Table 1 in terms of chromatographic conditions (mobile phase and gradient and analytical column), detection, and quantification in each method for different cereal matrices.

\section{Hidden Mycotoxins Characterization}

Mycotoxin derivatives that are undetectable by conventional analytical techniques are designated masked mycotoxins $[161,162]$. Chemical transformations that generate masked mycotoxins are catalyzed by plant enzymes [38]. The group of masked mycotoxins comprises both extractable conjugated and bound (nonextractable) varieties. Bound mycotoxins are covalently or noncovalently attached to polymeric carbohydrate or protein matrices [38, 39]. Extractable conjugated mycotoxins can be detected by appropriate analytical methods when their structure is known and analytical standards are available. Bound mycotoxins, however, are not directly accessible and have to be unconventional from the matrix by chemical or enzymatic treatment before chemical analysis.

Among all modified mycotoxins, most occurrence data exist for deoxynivalenol-3- $\beta$-d-glucopyranoside (D3G), which was detected in naturally contaminated maize and wheat for the first time in 2005 [163]. Cereal contamination with D3G was reported to occur worldwide according to surveys from the UK, [164], the Czech Republic [165], China [166], and Canada [167]. Subsequent surveys showed intermittently high contaminations of D3G exceeding $1000 \mu \mathrm{g} /$ $\mathrm{kg}$ in naturally contaminated wheat [122]. D3G also has been detected in oats and barley $[122,168]$.

D3G was noticed in wheat bread; nevertheless, the levels were below the LOQ $(100 \mu \mathrm{g} / \mathrm{kg})$. Using a more sensitive method, $80 \%$ of 116 flour, breakfast cereal, and snack samples from the Czech market analyzed were found to be contaminated with D3G at concentrations ranging from 5 to $72 \mu \mathrm{g} / \mathrm{kg}$ [164]. Interestingly, Sasanya et al. [169] reported that some wheat samples contained significantly higher values (up to 2.7 fold) of D3G compared to DON. The linearity $\left(r^{2}\right)$ of D3G was 0.914 ; recovery was $70.0 \%$, while LOQ and LOD were 1 and $0.51 \mathrm{~g} / \mathrm{kg}$, respectively [169]. On the other hand, Berthiller et al. [162] reported a method detection limit of $0.012 \mathrm{~g} / \mathrm{ml}$ for D3G in purified sample extracts, corresponding to $0.02 \mathrm{~g} / \mathrm{g}$ in contaminated cereals. Berthiller et al. [162] also estimated their LOD from the signal intensity of their standards, based on the limited ion suppression they observed. The pigment LOQ and LOD were 4.3 and $0.0005 \mathrm{~g} / \mathrm{kg}$, respectively. Good linearity for the pigment standard curve $\left(R^{2} 0.999\right)$ was also observed [162].

Suman et al. [170] reported the development of a liquid chromatography/linear ion trap mass spectrometry method capable of determining D3G. Samples were extracted with a mixture of methanol/water $(80: 20 ; \mathrm{v} / \mathrm{v})$ and cleaned up using immunoaffinity columns. Chromatographic separation was performed using a core-shell $\mathrm{C}_{18}$ column with an aqueous acetic acid/methanol mixture as the mobile phase under gradient conditions. The method was in-house validated on a bread matrix as follows: matrix-matched linearity $\left(r^{2}>0.99\right)$ was recognized in the range of $10-200 \mu \mathrm{g} / \mathrm{kg}$; trueness expressed as recovery was close to $90 \%$; good intermediate precision (overall RSD $<9 \%$ ) and adequate LOD and LOQ limits ( 4 and $11 \mu \mathrm{g} / \mathrm{kg}$, respectively) were realized. The reliability of the method was finally demonstrated in bread, cracker, biscuit, and minicake commodities, resulting in relatively low levels of DON-3G, which were not higher than $30 \mu \mathrm{g} / \mathrm{kg}$ [170].

Dall'Asta et al. [171] developed an LC-ESI-MS/MS method for the simultaneous detection of the main fumonisins and their hydrolyzed derivatives allowing for a simplified sample preparation without previous clean-up. The method has a very low LOQ $\left(10 \mu \mathrm{g} / \mathrm{kg}\right.$ for $\mathrm{FB}_{1}, 12 \mu \mathrm{g} / \mathrm{kg}$ for $\mathrm{FB}_{2}$ and $\mathrm{FB}_{3}, 70 \mu \mathrm{g} / \mathrm{kg}$ for $\mathrm{HFB}_{1}, \mathrm{HFB}_{2}$, and $\mathrm{HFB}_{3}$ in maize flour) and a very good recovery for all the analytes. The sensitivity was good for all the considered analytes being the LOD and LOQ values comparable with those from other recently published LC-MS/MS methods, although those methods required a sample purification and preconcentration step $[88,89,172]$. Bound fumonisins were found to be present not only in thermally treated maize-based products but also in mild processed or even raw products (pasta, bread, cakes, crisps, and flour) and they were always present in almost similar or even higher amounts than the free forms [171]. Osborne fractions of maize proteins showed that fumonisins were particularly bound to prolamins and glutelins [171].

$\mathrm{Hu}$ et al. [173] investigated free and hidden fumonisins in raw maize and maize-based products from China. A total of 58 samples were analyzed using LC-MS/MS. Among all the samples, $66 \%$ were contaminated with free fumonisins above limits of quantitation, and a higher percentage of $86 \%$ was found for total fumonisins (free + hidden). The response functions for $\mathrm{FB}_{1}, \mathrm{FB}_{2}, \mathrm{HFB}_{1}$, and $\mathrm{HFB}_{2}$ showed that all the $R^{2}$ were greater than 0.99 , suggesting good linearity. The LODs of FBs and HFBs were between 6 and $7 \mu \mathrm{g} / \mathrm{kg}$, and the LOQs were between 23 and $28 \mu \mathrm{g} / \mathrm{kg}$ [173]; these results showed that the present method was about 4 times more sensitive than that reported by Oliveira et al. [174]. In comparison, by using isotope-labeled internal standards, Bryła et al. [175] found LOQs of $22 \mu \mathrm{g} / \mathrm{kg}$ for HFBs, which were similarly sensitive as the study of $\mathrm{Hu}$ et al. [173].

Andrade et al. [176] have validated multimycotoxin method based on extraction with acidified acetonitrile and LC-ESI ${ }^{+}$-MS/MS analysis. The LOQs ranged from 0.5 to $121 \mu \mathrm{g} / \mathrm{kg}$ and proved to be suitable for the multimycotoxin analysis in wheat, maize, and rice products. Bound/hidden fumonisins were determined after extraction of the free forms using the multimycotoxin method, followed by a basic hydrolysis of the unextracted bound/hidden and solid-liquid extraction with low temperature purification (SLE-LTP). Recoveries for $\mathrm{HFB}_{1}, \mathrm{HFB}_{2}$. and $\mathrm{HFB}_{3}$ were evaluated in six replicates fortified with the prepared standards at levels of $1.2,1.8$, and $2.5 \mathrm{~g} / \mathrm{kg}$, respectively. Recoveries were $75.6 \%$ (RSD of $6.6 \%$ ) for $\mathrm{HFB}_{1}, 108.0 \%$ (RSD of $10.6 \%$ ) for $\mathrm{HFB}_{2}$, and $74.9 \%$ (RSD of $12.2 \%$ ) for $\mathrm{HFB}_{3}$. 


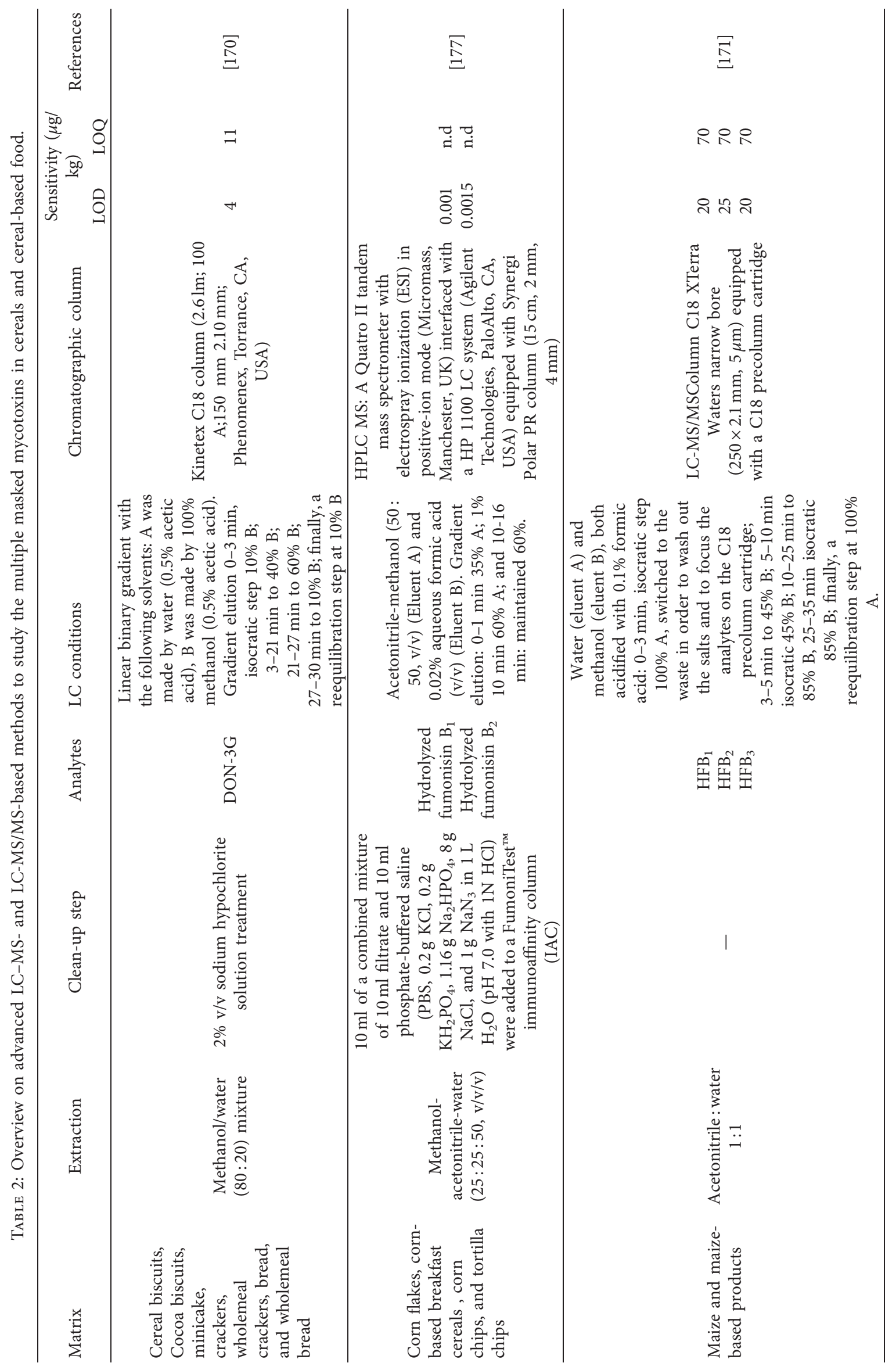




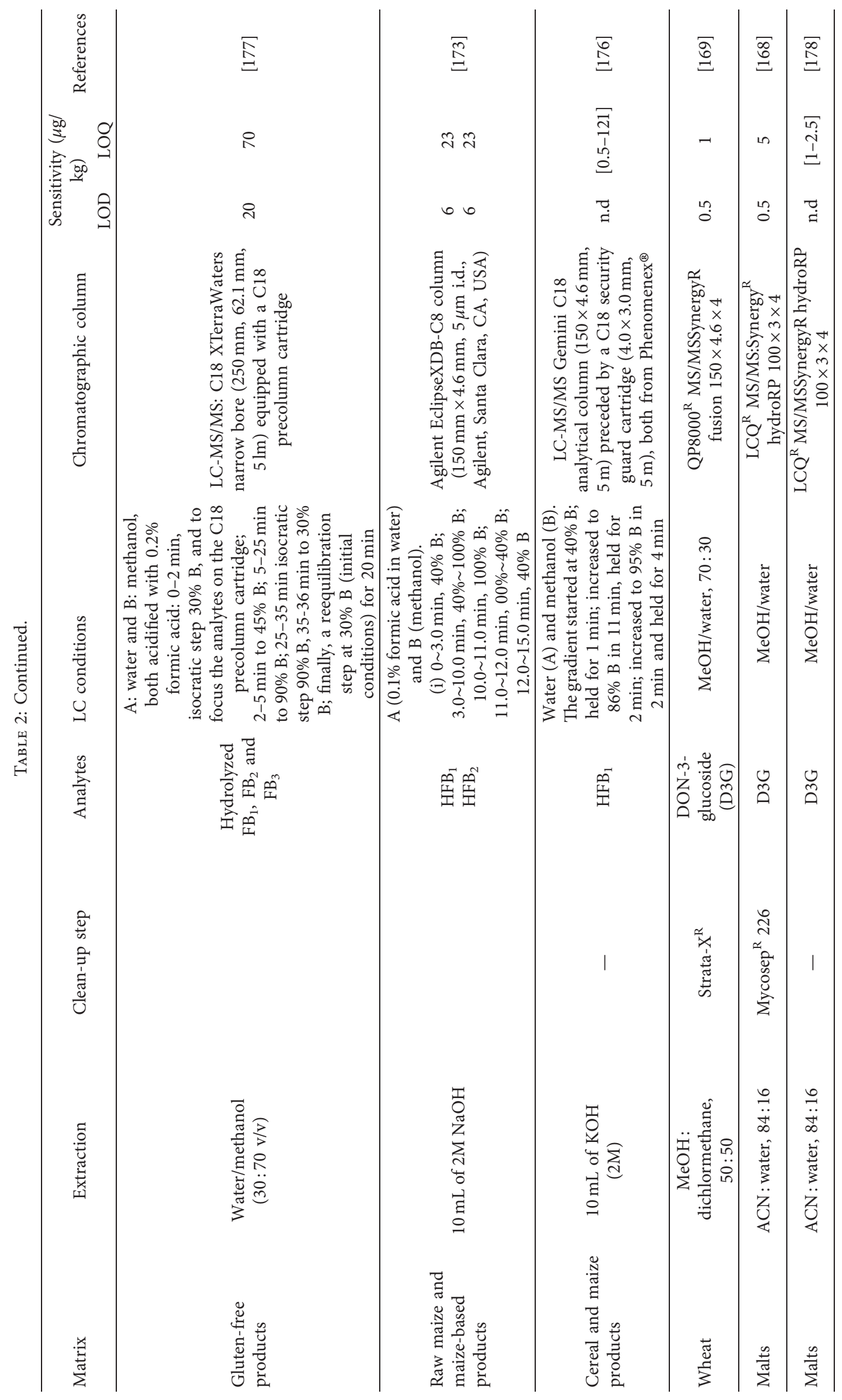


Table 2 presents a well-detailed description of the analytical method mentioned above for masked mycotoxin from cereals and related foodstuffs.

\section{Conclusion}

Cereals and related foodstuffs could be contaminated by diverse toxin-producing fungal species that are linked to severe and chronic toxic effects for both humans and animals. Consequently, many successful methods, such as LCMS/MS, have been identified in this area. LC-MS/MS continues to play a central role in the determination of mycotoxins in cereals and related foodstuffs unless a drastically different approach to distinct complex mixtures is advanced. In this context, smaller amounts of samples can be processed faster than ever. To quantify free and masked mycotoxins in cereals and related foodstuffs, separation stayed as important as ever. The great increases in sensitivity and selectivity of LC-MS instruments have made a significant contribution in qualitative and quantitative determination of mycotoxins in in cereals and related foodstuffs. In this line, the increasing use of hybrid mass spectrometers, incorporating mass analyzers that are capable of high mass resolution and accurate mass measurements, mitigates some of the problems associated with selectivity and identification, but further technological development of LC-MS interfaces is required to minimize matrix effects. However, maintaining confidence in the assignment of identity and isobaric interference are still the major limitations for LC-MS methods used for the quantification and identification of mycotoxins in cereals and related foodstuffs. Eventually, interested chemists could keep continuing research and contribute to develop and suggest new and advanced analytical techniques to ensure higher sensitivity and obtain solutions to several issues related to mycotoxins.

\section{Data Availability}

The data used to support the findings of this study are available from the corresponding author upon request.

\section{Conflicts of Interest}

The authors declare no conflicts of interest.

\section{Acknowledgments}

The Tunisian Ministry of Higher Education and Scientific Research, Tunisia, funded this research.

\section{References}

[1] H. J. Lee and D. Ryu, "Worldwide occurrence of mycotoxins in cereals and cereal-derived food products: public health perspectives of their co-occurrence," Journal of Agricultural and Food Chemistry, vol. 65, no. 33, pp. 7034-7051, 2017.

[2] S. Mishra, K. M. Ansari, P. D. Dwivedi, H. P. Pandey, and M. Das, "Occurrence of deoxynivalenol in cereals and exposure risk assessment in Indian population," Food Control, vol. 30, no. 2, pp. 549-555, 2013.
[3] A. Nematollahi, M. Kamankesh, H. Hosseini, J. Ghasemi, F. Hosseini-Esfahani, and A. Mohammadi, "Investigation and determination of acrylamide in the main group of cereal products using advanced microextraction method coupled with gas chromatography-mass spectrometry," Journal of Cereal Science, vol. 87, pp. 157-164, 2019.

[4] A. M. Khaneghah, A. Farhadi, A. Nematollahi, Y. Vasseghian, and Y. Fakhri, "A systematic review and meta-analysis to investigate the concentration and prevalence of trichothecenes in the cereal-based food," Trends in Food Science \& Technology, vol. 102, pp. 193-202, 2020.

[5] A. Heshmati, T. Zohrevand, A. M. Khaneghah, A. S. Mozaffari Nejad, and A. S. Sant'Ana, "Co-occurrence of aflatoxins and ochratoxin A in dried fruits in Iran: dietary exposure risk assessment," Food and Chemical Toxicology, vol. 106, pp. 202-208, 2017.

[6] N. N. A. Kyei, D. Boakye, and S. Gabrysch, "Maternal mycotoxin exposure and adverse pregnancy outcomes: a systematic review," Mycotoxin Research, vol. 36, no. 2, pp. 243-255, 2020.

[7] S. Agriopoulou, E. Stamatelopoulou, and T. Varzakas, "Advances in occurrence, importance, and mycotoxin control strategies: prevention and detoxification in foods," Foods, vol. 9, no. 2, pp. 137-184, 2020.

[8] S. Marin, A. J. Ramos, G. Cano-Sancho, and V. Sanchis, "Mycotoxins: occurrence, toxicology, and exposure assessment," Food and Chemical Toxicology, vol. 60, pp. 218-237, 2013.

[9] H. Kebede, H. Abbas, D. Fisher, and N. Bellaloui, "Relationship between aflatoxin contamination and physiological responses of corn plants under drought and heat stress," Toxins, vol. 4, no. 11, pp. 1385-1403, 2012.

[10] H. Hussein and J. M. Brasel, "Toxicity, metabolism, and impact of mycotoxins on humans and animals," Toxicology, vol. 167, no. 2, pp. 101-134, 2001.

[11] L. Aldars-García, M. Berman, J. Ortiz, A. J. Ramos, and S. Marín, "Probability models for growth and aflatoxin B1 production as affected by intraspecies variability in Aspergillus flavus," Food Microbiology, vol. 72, pp. 166-175, 2018.

[12] P. Rodrigues, A. Venâncio, and N. Lima, "Mycobiota and mycotoxins of almonds and chestnuts with special reference to aflatoxins," Food Research International, vol. 48, no. 1, pp. 76-90, 2012.

[13] H. Rastegar, S. Shoeibi, H. Yazdanpanah et al., "Removal of aflatoxin B1 by roasting with lemon juice and/or citric acid in contaminated pistachio nuts," Food Control, vol. 71, pp. 279-284, 2017.

[14] A. Reyneri, "The role of climatic condition on micotoxin production in cereal," Veterinary Research Communications, vol. 30, no. 1, pp. 87-92, 2006.

[15] A. M. Khaneghah, Y. Fakhri, H. M. Gahruie, M. Niakousari, and A. S. Sant'Ana, "Mycotoxins in cereal-based products during 24 years (1983-2017): a global systematic review," Trends in Food Science \& Technology, vol. 91, pp. 95-105, 2019.

[16] I. Kamika, K.-t.-N. Ngbolua, and M. Tekere, "Occurrence of aflatoxin contamination in maize throughout the supply chain in the democratic republic of Congo," Food Control, vol. 69, pp. 292-296, 2016.

[17] L. Escrivá, S. Oueslati, G. Font, and L. Manyes, "Alternaria mycotoxins in food and feed: an overview," Journal of Food Quality, vol. 2017, Article ID 1569748, 20 pages, 2017.

[18] V. G. G. Uka, G. G. N. Moore, D. Arroyo-Manzanares, S. M. D. G. Nebija, G. De Saeger, and J. D. Di Mavungu, 
"Secondary metabolite dereplication and phylogenetic analysis identify various emerging mycotoxins and reveal the high intra species diversity in Aspergillus flavus," Frontiers in Microbiology, vol. 10, p. 667 686, 2019.

[19] M. R. Greeff-Laubscher, I. Beukes, G. J. Marais, and K. Jacobs, "Mycotoxin production by three different toxigenic fungi genera on formulated abalone feed and the effect of an aquatic environment on fumonisins," Mycology, vol. 11, no. 2, pp. 105-117, 2020.

[20] F. B. Campagnollo, K. C. Ganev, A. M. Khaneghah et al., "The occurrence and effect of unit operations for dairy products processing on the fate of aflatoxin M1: a review," Food Control, vol. 68, pp. 310-329, 2016.

[21] A. M. Khaneghah, L. M. Martins, A. M. von Hertwig, R. Bertoldo, and A. S. Sant'Ana, "Deoxynivalenol and its masked forms: characteristics, incidence, control and fate during wheat and wheat based products processing-a review," Trends in Food Science \& Technology, vol. 71, pp. 13-24, 2018.

[22] V. Kagot, S. Okoth, M. De Boevre, and S. De Saeger, "Biocontrol of Aspergillus and Fusarium mycotoxins in Africa: benefits and limitations," Toxins, vol. 11, no. 2, pp. 109-117, 2019.

[23] A. Alshannaq and J.-H. Yu, "Occurrence, toxicity, and analysis of major mycotoxins in food," International Journal of Environmental Research and Public Health, vol. 14, no. 6, pp. 632-651, 2017.

[24] B. R. Rushing and M. I. Selim, "Aflatoxin B1: a review on metabolism, toxicity, occurrence in food, occupational exposure, and detoxification methods," Food and Chemical Toxicology, vol. 124, pp. 81-100, 2019.

[25] L. Gambacorta, D. Magistà, G. Perrone, S. Murgolo, A. F. Logrieco, and M. Solfrizzo, "Co-occurrence of toxigenic moulds, aflatoxins, ochratoxin A, Fusarium and Alternaria mycotoxins in fresh sweet peppers (Capsicum annuum) and their processed products," World Mycotoxin Journal, vol. 11, no. 1, pp. 159-174, 2018.

[26] S. W. Gratz, R. Dinesh, T. Yoshinari et al., "Masked trichothecene and zearalenone mycotoxins withstand digestion and absorption in the upper GI tract but are efficiently hydrolyzed by human gut microbiota in vitro," Molecular Nutrition \& Food Research, vol. 61, no. 4, Article ID 1600680, 2017.

[27] L. Escrivá, G. Font, L. Manyes, and H. Berrada, "Studies on the presence of mycotoxins in biological samples: an overview," Toxins, vol. 9, no. 8, pp. 251-283, 2017.

[28] G. Winter and L. Pereg, "A review on the relation between soil and mycotoxins: effect of aflatoxin on field, food and finance," European Journal of Soil Science, vol. 70, pp. 882897, 2019.

[29] S. A. O. Adeyeye, "Aflatoxigenic fungi and mycotoxins in food: a review," Critical Reviews in Food Science and $\mathrm{Nu}$ trition, vol. 60, no. 5, pp. 709-721, 2020.

[30] G. Conte, M. Fontanelli, F. Galli, L. Cotrozzi, L. Pagni, and E. Pellegrini, "Mycotoxins in feed and food and the role of ozone in their detoxification and degradation: an update," Toxins, vol. 12, no. 8, pp. 486-404, 2020.

[31] J. M. Oteiza, A. M. Khaneghah, F. B. Campagnollo et al., "Influence of production on the presence of patulin and ochratoxin A in fruit juices and wines of Argentina," LWT, vol. 80, pp. 200-207, 2017.

[32] R. Köppen, M. Koch, D. Siegel, S. Merkel, R. Maul, and I. Nehls, "Determination of mycotoxins in foods: current state of analytical methods and limitations," Applied
Microbiology and Biotechnology, vol. 86, no. 6, pp. 15951612, 2010.

[33] I. Slobodchikova and D. Vuckovic, "Liquid chromatography-high resolution mass spectrometry method for monitoring of 17 mycotoxins in human plasma for exposure studies," Journal of Chromatography A, vol. 1548, pp. 51-63, 2018.

[34] K. Jiang, Q. Huang, K. Fan et al., "Reduced graphene oxide and gold nanoparticle composite-based solid-phase extraction coupled with ultra-high-performance liquid chromatography-tandem mass spectrometry for the determination of 9 mycotoxins in milk," Food Chemistry, vol. 264, pp. 218-225, 2018.

[35] S. A. Tittlemier, B. Cramer, C. Dall'Asta et al., "Developments in mycotoxin analysis: an update for 2017-2018," World Mycotoxin Journal, vol. 12, no. 1, pp. 3-29, 2019.

[36] V. Moreno, M. Zougagh, and Á. Ríos, "Hybrid nanoparticles based on magnetic multiwalled carbon nanotube-nanoC ${ }_{18} \mathrm{SiO}_{2}$ composites for solid phase extraction of mycotoxins prior to their determination by LC-MS," Microchimica Acta, vol. 183, no. 2, pp. 871-880, 2016.

[37] H. Zhao, X. Chen, C. Shen, and B. Qu, "Determination of 16 mycotoxins in vegetable oils using a QuEChERS method combined with high-performance liquid chromatographytandem mass spectrometry," Food Additives \& Contaminants: Part A, vol. 34, no. 2, pp. 255-264, 2017.

[38] F. Berthiller, C. Crews, C. Dall'Asta et al., "Masked mycotoxins: a review," Molecular Nutrition \& Food Research, vol. 57, no. 1, pp. 165-186, 2013.

[39] F. Berthiller, R. Schuhmacher, G. Adam, and R. Krska, "Formation, determination and significance of masked and other conjugated mycotoxins," Analytical and Bioanalytical Chemistry, vol. 395, no. 5, pp. 1243-1252, 2009.

[40] P. Kovalsky, G. Kos, K. Nährer et al., "Co-occurrence of regulated, masked and emerging mycotoxins and secondary metabolites in finished feed and maize-an extensive survey," Toxins, vol. 8, no. 12, pp. 363-391, 2016.

[41] A. M. Khaneghah, M. H. Kamani, Y. Fakhri, C. F. S. C. Coppa, C. A. F. de Oliveira, and A. S. Sant'Ana, "Changes in masked forms of deoxynivalenol and their cooccurrence with culmorin in cereal-based products: a systematic review and meta-analysis," Food Chemistry, vol. 294, pp. 587-596, 2019.

[42] B. Kluger, C. Bueschl, M. Lemmens et al., "Stable isotopic labelling-assisted untargeted metabolic profiling reveals novel conjugates of the mycotoxin deoxynivalenol in wheat," Analytical and Bioanalytical Chemistry, vol. 405, no. 15, pp. 5031-5036, 2013.

[43] E. Varga, G. Wiesenberger, C. Hametner et al., "New tricks of an old enemy: isolates of Fusarium graminearum produce a type A trichothecene mycotoxin," Environmental Microbiology, vol. 17, no. 8, pp. 2588-2600, 2015.

[44] M. De Boevre, J. D. Di Mavungu, P. Maene et al., "Development and validation of an LC-MS/MS method for the simultaneous determination of deoxynivalenol, zearalenone, $\mathrm{T}$-2-toxin and some masked metabolites in different cereals and cereal-derived food," Food Additives \& Contaminants: Part A, vol. 29, no. 5, pp. 819-835, 2012.

[45] M. De Boevre, L. Jacxsens, C. Lachat et al., "Human exposure to mycotoxins and their masked forms through cereal-based foods in Belgium," Toxicology Letters, vol. 218, no. 3, pp. 281-292, 2013.

[46] H. Nakagawa, K. Ohmichi, S. Sakamoto et al., "Detection of a new Fusarium masked mycotoxin in wheat grain by high- 
resolution LC-Orbitrap ${ }^{\mathrm{TM}}$ MS," Food Additives \& Contaminants: Part A, vol. 28, no. 10, pp. 1447-1456, 2011.

[47] H. E. Ok, S.-W. Choi, H. J. Chang, M.-S. Chung, and H. S. Chun, "Occurrence of five 8-ketotrichothecene mycotoxins in organically and conventionally produced cereals collected in Korea," Food Control, vol. 22, no. 10, pp. 1647-1652, 2011.

[48] B. Maestroni and A. Cannavan, "Sampling strategies to control mycotoxins," in Determining Mycotoxins and Mycotoxigenic Fungi in Food and Feed, pp. 3-36, Woodhead Publishing, Cambridge, UK, 2011.

[49] A. C. Weaver, N. Adams, and A. Yiannikouris, "Invited review: use of technology to assess and monitor multimycotoxin and emerging mycotoxin challenges in feedstuffs," Applied Animal Science, vol. 36, no. 1, pp. 19-25, 2020.

[50] European Union, "Commission regulation (EU) no. 519/ 2014 of 16 May 2014 amending regulation (EC) no. 401/2006 as regards methods of sampling of large lots, spices and food supplements, performance criteria for T-2, HT-2 toxin and citrinin and screening methods of analysis," Official Journal of the European Union, vol. 29, no. L147, pp. 29-43, 2014.

[51] D. Garon, E. Richard, L. Sage, V. Bouchart, D. Pottier, and P. Lebailly, "Mycoflora and multimycotoxin detection in corn silage: experimental study," Journal of Agricultural and Food Chemistry, vol. 54, no. 9, pp. 3479-3484, 2006.

[52] V. M. T. Lattanzio, M. Solfrizzo, S. Powers, and A. Visconti, "Simultaneous determination of aflatoxins, ochratoxin A and Fusarium toxins in maize by liquid chromatography/tandem mass spectrometry after multitoxin immunoaffinity cleanup," Rapid Communications in Mass Spectrometry, vol. 21, no. 20, pp. 3253-3261, 2007.

[53] M. Sulyok, F. Berthiller, R. Krska, and R. Schuhmacher, "Development and validation of a liquid chromatography/ tandem mass spectrometric method for the determination of 39 mycotoxins in wheat and maize," Rapid Communications in Mass Spectrometry, vol. 20, no. 18, pp. 2649-2659, 2006.

[54] L. Zhang, X.-W. Dou, C. Zhang, A. Logrieco, and M.-H. Yang, "A review of current methods for analysis of mycotoxins in herbal medicines," Toxins, vol. 10, no. 2, pp. 65-103, 2018.

[55] G. P. Munkvold, S. Arias, I. Taschl, and C. Gruber-Dorninger, "Mycotoxins in corn: occurrence, impacts, and management," in Corn, pp. 235-287, AACC International Press, Saint Paul, MN, USA, 2019.

[56] V. L. Pereira, J. O. Fernandes, and S. C. Cunha, "Mycotoxins in cereals and related foodstuffs: a review on occurrence and recent methods of analysis," Trends in Food Science \& Technology, vol. 36, no. 2, pp. 96-136, 2014.

[57] V. Scarpino, A. Reyneri, and M. Blandino, "Development and comparison of two multiresidue methods for the determination of 17 Aspergillus and Fusarium mycotoxins in cereals using HPLC-ESI-TQ-MS/MS," Frontiers in Microbiology, vol. 10, pp. 361-371, 2019.

[58] N. W. Turner, H. Bramhmbhatt, M. Szabo-Vezse, A. Poma, R. Coker, and S. A. Piletsky, "Analytical methods for determination of mycotoxins: an update (2009-2014)," Analytica Chimica Acta, vol. 901, pp. 12-33, 2015.

[59] I. Reinholds, I. Pugajeva, E. Bogdanova, J. Jaunbergs, and V. Bartkevics, "Recent applications of carbonaceous nanosorbents for the analysis of mycotoxins in food by liquid chromatography: a short review," World Mycotoxin Journal, vol. 12, no. 1, pp. 31-43, 2019.
[60] J. Singh and A. Mehta, "Rapid and sensitive detection of mycotoxins by advanced and emerging analytical methods: a review," Food Science \& Nutrition, vol. 8, no. 5, pp. 2183-2204, 2020.

[61] R. Colombo and A. Papetti, "Pre-concentration and analysis of mycotoxins in food samples by capillary electrophoresis," Molecules, vol. 25, no. 15, pp. 3441-3459, 2020.

[62] N. Ünüsan, "Systematic review of mycotoxins in food and feeds in Turkey," Food Control, vol. 97, pp. 1-14, 2019.

[63] A. Malachová, M. Stránská, M. Václavíková et al., "Advanced LC-MS-based methods to study the co-occurrence and metabolization of multiple mycotoxins in cereals and cerealbased food," Analytical and Bioanalytical Chemistry, vol. 410, no. 3, pp. 801-825, 2018.

[64] M. Amirahmadi, S. Shoeibi, H. Rastegar, M. Elmi, and A. Mousavi Khaneghah, "Simultaneous analysis of mycotoxins in corn flour using LC/MS-MS combined with a modified QuEChERS procedure," Toxin Reviews, vol. 37, no. 3, pp. 187-195, 2018.

[65] B. Zhang, X. Chen, S.-Y. Han et al., "Simultaneous analysis of 20 mycotoxins in grapes and wines from hexi corridor region (China): based on a QuEChERS-UHPLC-MS/MS method," Molecules, vol. 23, no. 8, pp. 1926-1942, 2018.

[66] M.-Y. Wu, M. E. Mead, M.-K. Lee et al., "Systematic dissection of the evolutionarily conserved WetA developmental regulator across a genus of filamentous fungi," MBio, vol. 9, no. 4, Article ID e01130, 2018.

[67] C. Santos Pereira, S. C. Cunha, and J. O. Fernandes, "Prevalent mycotoxins in animal feed: occurrence and analytical methods," Toxins, vol. 11, no. 5, pp. 290-351, 2019.

[68] H. Peng, Y. Chang, R. C. Baker, and G. Zhang, "Interference of mycotoxin binders with ELISA, HPLC and LC-MS/MS analysis of aflatoxins in maize and maize gluten," Food Additives \& Contaminants: Part A, vol. 37, no. 3, pp. 496506, 2020.

[69] H.-Y. Wang, Y.-L. Yang, Y. Wang, S.-F. Zhang, and L. Li, "Development of disk-shaped monolithic microplates for detecting multiple mycotoxins," Analytical Methods, vol. 11, no. 48, pp. 6084-6091, 2019.

[70] H. Shi, S. Li, Y. Bai, L. L. Prates, Y. Lei, and P. Yu, "Mycotoxin contamination of food and feed in China: occurrence, detection techniques, toxicological effects and advances in mitigation technologies," Food Control, vol. 91, pp. 202-215, 2018.

[71] M. A. Haque, Y. Wang, Z. Shen, X. Li, M. K. Saleemi, and C. He, "Mycotoxin contamination and control strategy in human, domestic animal and poultry: a review," Microbial Pathogenesis, vol. 142, Article ID 104095, 2020.

[72] A. Roseanu, L. Jecu, M. Badea, and R. W. Evans, "Mycotoxins: an overview on their quantification methods," Romanian Journal of Biochemistry, vol. 47, no. 1, pp. 79-86, 2010.

[73] S. Agriopoulou, E. Stamatelopoulou, and T. Varzakas, "Advances in analysis and detection of major mycotoxins in foods," Foods, vol. 9, no. 4, pp. 518-540, 2020.

[74] M. Pascale, A. De Girolamo, V. Lippolis, J. Stroka, H. G. J. Mol, and V. M. T. Lattanzio, "Performance evaluation of LC-MS methods for multimycotoxin determination," Journal of AOAC International, vol. 102, no. 6, pp. 1708-1720, 2019.

[75] S. J. Hird, B. P.-Y. Lau, R. Schuhmacher, and R. Krska, "Liquid chromatography-mass spectrometry for the determination of chemical contaminants in food," TrAC: Trends in Analytical Chemistry, vol. 59, pp. 59-72, 2014. 
[76] P. Herrero, N. Cortés-Francisco, F. Borrull, J. Caixach, E. Pocurull, and R. M. Marcé, "Comparison of triple quadrupole mass spectrometry and orbitrap high-resolution mass spectrometry in ultrahigh performance liquid chromatography for the determination of veterinary drugs in sewage: benefits and drawbacks," Journal of Mass Spectrometry, vol. 49, no. 7, pp. 585-596, 2014.

[77] A. Kaufmann, P. Butcher, K. Maden, S. Walker, and M. Widmer, "Quantitative and confirmative performance of liquid chromatography coupled to high-resolution mass spectrometry compared to tandem mass spectrometry," Rapid Communications in Mass Spectrometry, vol. 25, no. 7, pp. 979-992, 2011.

[78] A. R. Fontana, I. Rodríguez, M. Ramil, J. C. Altamirano, and R. Cela, "Liquid chromatography time-of-flight mass spectrometry following sorptive microextraction for the determination of fungicide residues in wine," Analytical and Bioanalytical Chemistry, vol. 401, no. 2, pp. 767-775, 2011.

[79] A. Kaufmann, P. Butcher, K. Maden, S. Walker, and M. Widmer, "Quantification of anthelmintic drug residues in milk and muscle tissues by liquid chromatography coupled to orbitrap and liquid chromatography coupled to tandem mass spectrometry," Talanta, vol. 58, no. 2, pp. 991-1000, 2011.

[80] T. Rejczak and T. Tuzimski, "Recent trends in sample preparation and liquid chromatography/mass spectrometry for pesticide residue analysis in food and related matrixes," Journal of AOAC International, vol. 98, no. 5, pp. 1143-1162, 2015.

[81] J. Rubert, K. J. James, J. Mañes, and C. Soler, “Applicability of hybrid linear ion trap-high resolution mass spectrometry and quadrupole-linear ion trap-mass spectrometry for mycotoxin analysis in baby food," Journal of Chromatography A, vol. 1223, pp. 84-92, 2012.

[82] J. Tolosa, G. Font, J. Mañes, and E. Ferrer, "Natural occurrence of emerging Fusarium mycotoxins in feed and fish from aquaculture," Journal of Agricultural and Food Chemistry, vol. 62, no. 51, pp. 12462-12470, 2014.

[83] M. Ghaste, R. Mistrik, and V. Shulaev, "Applications of Fourier transform ion cyclotron resonance (FT-ICR) and orbitrap based high resolution mass spectrometry in metabolomics and lipidomics," International Journal of Molecular Sciences, vol. 17, no. 6, pp. 816-837, 2016.

[84] M. Rychlik, B. Kanawati, C. Roullier-Gall et al., "Foodomics assessed by Fourier transform mass spectrometry," in Fundamentals and Applications of Fourier Transform Mass Spectrometry, pp. 651-677, Elsevier, Amsterdam, Netherlands, 2019.

[85] S. Biselli and C. Hummert, "Development of a multicomponent method forFusariumtoxins using LC-MS/MS and its application during a survey for the content of T-2 toxin and deoxynivalenol in various feed and food samples," Food Additives and Contaminants, vol. 22, no. 8, pp. 752-760, 2005.

[86] F. Berthiller, R. Schuhmacher, G. Buttinger, and R. Krska, "Rapid simultaneous determination of major type A- and B-trichothecenes as well as zearalenone in maize by high performance liquid chromatography-tandem mass spectrometry," Journal of Chromatography A, vol. 1062, no. 2, pp. 209-216, 2005.

[87] F. Soleimany, S. Jinap, and F. Abas, "Determination of mycotoxins in cereals by liquid chromatography tandem mass spectrometry," Food Chemistry, vol. 130, no. 4, pp. 1055-1060, 2012.
[88] C. Cavaliere, P. Foglia, E. Pastorini, R. Samperi, and A. Laganà, "Development of a multiresidue method for analysis of major Fusarium mycotoxins in corn meal using liquid chromatography/tandem mass spectrometry," Rapid Communications in Mass Spectrometry, vol. 19, no. 14, pp. 2085-2093, 2005.

[89] B. Delmulle, S. De Saeger, A. Adams, N. De Kimpe, and C. Van Peteghem, "Development of a liquid chromatography/tandem mass spectrometry method for the simultaneous determination of 16 mycotoxins on cellulose filters and in fungal cultures," Rapid Communications in Mass Spectrometry, vol. 20, no. 5, pp. 771-776, 2006.

[90] M. Castro-Puyana, R. Pérez-Míguez, L. Montero, and M. Herrero, "Reprint of: application of mass spectrometrybased metabolomics approaches for food safety, quality and traceability," TrAC: Trends in Analytical Chemistry, vol. 96, pp. 62-78, 2017.

[91] G. Hopfgartner, E. Varesio, V. Tschäppät, C. Grivet, E. Bourgogne, and L. A. Leuthold, "Triple quadrupole linear ion trap mass spectrometer for the analysis of small molecules and macromolecules," Journal of Mass Spectrometry, vol. 39, no. 8, pp. 845-855, 2004.

[92] W. A. Abia, B. Warth, M. Sulyok et al., "Determination of multi-mycotoxin occurrence in cereals, nuts and their products in Cameroon by liquid chromatography tandem mass spectrometry (LC-MS/MS)," Food Control, vol. 31, no. 2, pp. 438-453, 2013.

[93] A. Malachová, M. Sulyok, E. Beltrán, F. Berthiller, and R. Krska, "Optimization and validation of a quantitative liquid chromatography-tandem mass spectrometric method covering 295 bacterial and fungal metabolites including all regulated mycotoxins in four model food matrices," Journal of Chromatography A, vol. 1362, pp. 145-156, 2014.

[94] E. Varga, T. Glauner, F. Berthiller, R. Krska, R. Schuhmacher, and M. Sulyok, "Development and validation of a (semi-) quantitative UHPLC-MS/MS method for the determination of 191 mycotoxins and other fungal metabolites in almonds, hazelnuts, peanuts and pistachios," Analytical and Bioanalytical Chemistry, vol. 405, no. 15, pp. 5087-5104, 2013.

[95] K. Habler and M. Rychlik, "Multi-mycotoxin stable isotope dilution LC-MS/MS method for Fusarium toxins in cereals," Analytical and Bioanalytical Chemistry, vol. 408, no. 1, pp. 307-317, 2016.

[96] H. R. Morris, T. Paxton, A. Dell et al., "High sensitivity collisionally-activated decomposition tandem mass spectrometry on a novel quadrupole/orthogonal-acceleration time-of-flight mass spectrometer," Rapid Communications in Mass Spectrometry, vol. 10, no. 8, pp. 889-896, 1996.

[97] A. Leitner, M. Faini, F. Stengel, and R. Aebersold, "Crosslinking and mass spectrometry: an integrated technology to understand the structure and function of molecular machines," Trends in Biochemical Sciences, vol. 41, no. 1, pp. 20-32, 2016.

[98] J. V. Olsen, B. Macek, O. Lange, A. Makarov, S. Horning, and M. Mann, "Higher-energy C-trap dissociation for peptide modification analysis," Nature Methods, vol. 4, no. 9, pp. 709-712, 2007.

[99] K. W. von Bargen, L. Lohrey, B. Cramer, and H. U. Humpf, "Analysis of the Fusarium mycotoxin moniliformin in cereal samples using ${ }^{13} \mathrm{C}_{2}$-moniliformin and high-resolution mass spectrometry," Journal of Agricultural and Food Chemistry, vol. 60, no. 4, pp. 3586-3591, 2012.

[100] A. Michalski, E. Damoc, J. P. Hauschild et al., "Mass spectrometry-based proteomics using $\mathrm{Q}$ exactive, a high- 
performance benchtop quadrupole orbitrap mass spectrometer," Molecular \& Cellular Proteomics, vol. 10, no. 9, 2011.

[101] A. M. Evans, B. R. Bridgewater, Q. Liu et al., "High resolution mass spectrometry improves data quantity and quality as compared to unit mass resolution mass spectrometry in high-throughput profiling metabolomics," Metabolomics, vol. 4, no. 2, Article ID 1000132, 2014.

[102] V. M. T. Lattanzio, S. D. Gatta, M. Godula, and A. Visconti, "Quantitative analysis of mycotoxins in cereal foods by collision cell fragmentation-high-resolution mass spectrometry: performance and comparison with triple-stage quadrupole detection," Food Additives \& Contaminants: Part $A$, vol. 28, no. 10, pp. 1424-1437, 2011.

[103] G. J. Patti, O. Yanes, and G. Siuzdak, "Metabolomics: the apogee of the omics trilogy," Nature Reviews Molecular Cell Biology, vol. 13, no. 4, pp. 263-269, 2012.

[104] H. Li, Y. Cai, Y. Guo, F. Chen, and Z.-J. Zhu, "MetDIA: targeted metabolite extraction of multiplexed MS/MS spectra generated by data-independent acquisition," Analytical Chemistry, vol. 88, no. 17, pp. 8757-8764, 2016.

[105] D. S. Wishart, D. Tzur, C. Knox et al., "HMDB: the human metabolome database," Nucleic Acids Research, vol. 35, pp. D521-D526, 2007.

[106] C. A. Smith, G. O. Maille, E. J. Want et al., "METLIN," Therapeutic Drug Monitoring, vol. 27, no. 6, pp. 747-751, 2005.

[107] H. Horai, M. Arita, S. Kanaya et al., "MassBank: a public repository for sharing mass spectral data for life sciences," Journal of Mass Spectrometry, vol. 45, no. 7, pp. 703-714, 2010.

[108] W. Jia, L. Shi, F. Zhang, C. Fan, J. Chang, and X. Chu, "Multiplexing data independent untargeted workflows for mycotoxins screening on a quadrupole-orbitrap high resolution mass spectrometry platform," Food Chemistry, vol. 278, pp. 67-76, 2019.

[109] J. B. Renaud and M. W. Sumarah, "Data independent acquisition-digital archiving mass spectrometry: application to single kernel mycotoxin analysis of Fusarium graminearum infected maize," Analytical and Bioanalytical Chemistry, vol. 408, no. 12, pp. 3083-3091, 2016.

[110] C. Nerin, P. Alfaro, M. Aznar, and C. Domeño, "The challenge of identifying non-intentionally added substances from food packaging materials: a review," Analytica Chimica Acta, vol. 775, pp. 14-24, 2013.

[111] X. Zhu, Y. Chen, and R. Subramanian, "Comparison of information-dependent acquisition, SWATH, and MSAll techniques in metabolite identification study employing ultrahigh-performance liquid chromatography-quadrupole time-of-flight mass spectrometry," Analytical Chemistry, vol. 86, no. 2, pp. 1202-1209, 2014.

[112] X. Domingo-Almenara, J. R. Montenegro-Burke, H. P. Benton, and G. Siuzdak, "Annotation: a computational solution for streamlining metabolomics analysis," Analytical Chemistry, vol. 90, no. 1, pp. 480-489, 2018.

[113] J.-Y. Cho, H.-J. Lee, S.-K. Jeong, and Y. K. Paik, "Epsilon-Q: an automated analyzer interface for mass spectral library search and label-free protein quantification," Journal of Proteome Research, vol. 16, no. 12, pp. 4435-4445, 2017.

[114] A. Michalski, J. Cox, and M. Mann, "More than 100,000 detectable peptide species elute in single shotgun proteomics runs but the majority is inaccessible to data-dependent LCMS/MS," Journal of Proteome Research, vol. 10, no. 4, pp. 1785-1793, 2011.
[115] A. Panchaud, A. Scherl, S. A. Shaffer et al., "Precursor acquisition independent from ion count: how to dive deeper into the proteomics ocean," Analytical Chemistry, vol. 81, no. 15, pp. 6481-6488, 2009.

[116] H. Tsugawa, T. Cajka, T. Kind et al., "MS-DIAL: data-independent MS/MS deconvolution for comprehensive metabolome analysis," Nature Methods, vol. 12, no. 6, pp. 523-526, 2015.

[117] W. Zhang, R. Kiyonami, Z. Jiang, and W. Chen, "Quantitative analysis of targeted proteins in complex sample using novel data independent acquisition," Chinese Journal of Analytical Chemistry, vol. 42, no. 12, pp. 1750-1758, 2014.

[118] J. A. Vizcaíno, E. W. Deutsch, R. Wang et al., "ProteomeXchange provides globally coordinated proteomics data submission and dissemination," Nature Biotechnology, vol. 32, no. 3, pp. 223-226, 2014.

[119] C.-C. Tsou, D. Avtonomov, B. Larsen et al., "DIA-umpire: comprehensive computational framework for data-independent acquisition proteomics," Nature Methods, vol. 12, no. 3, pp. 258-264, 2015.

[120] J. D. Egertson, B. MacLean, R. Johnson, Y. Xuan, and M. J. MacCoss, "Multiplexed peptide analysis using dataindependent acquisition and skyline," Nature Protocols, vol. 10, no. 6, p. 887, 2015.

[121] B. J. A. Berendsen, R. S. Wegh, T. Meijer, and M. W. F. Nielen, "The assessment of selectivity in different quadrupole-orbitrap mass spectrometry acquisition modes," Journal of The American Society for Mass Spectrometry, vol. 26, no. 2, pp. 337-346, 2014.

[122] F. Berthiller, C. Dall'asta, R. Corradini et al., "Occurrence of deoxynivalenol and its 3- $\beta$-D-glucoside in wheat and maize," Food Additives \& Contaminants: Part A, vol. 26, no. 4, pp. 507-511, 2009.

[123] S. Y. Woo, S. Y. Ryu, F. Tian, S. Y. Lee, S. B. Park, and H. S. Chun, "Simultaneous determination of twenty mycotoxins in the Korean soybean paste doenjang by LC-MS/ MS with immunoaffinity cleanup," Toxins, vol. 11, no. 10, pp. 594-512, 2019.

[124] T. Bessaire, C. Mujahid, P. Mottier, and A. Desmarchelier, "Multiple mycotoxins determination in food by LC-MS/MS: an international collaborative study," Toxins, vol. 11, no. 11, pp. 658-675, 2019.

[125] F. Al-Taher, J. Cappozzo, J. Zweigenbaum, H. J. Lee, L. Jackson, and D. Ryu, "Detection and quantitation of mycotoxins in infant cereals in the U.S. market by LC-MS/ MS using a stable isotope dilution assay," Food Control, vol. 72, pp. 27-35, 2017

[126] M. C. Spanjer, P. M. Rensen, and J. M. Scholten, "LC-MS/MS multi-method for mycotoxins after single extraction, with validation data for peanut, pistachio, wheat, maize, cornflakes, raisins and figs," Food Additives \& Contaminants: Part A, vol. 25, no. 4, pp. 472-489, 2008

[127] M. Bolechová, K. Benešová, S. Běláková, J. Čáslavský, M. Pospíchalová, and R. Mikulíková, "Determination of seventeen mycotoxins in barley and malt in the Czech Republic," Food Control, vol. 47, pp. 108-113, 2015.

[128] F. Soleimany, S. Jinap, A. Faridah, and A. Khatib, "A UPLCMS/MS for simultaneous determination of aflatoxins, ochratoxin A, zearalenone, DON, fumonisins, T-2 toxin and HT-2 toxin, in cereals," Food Control, vol. 25, no. 2, pp. 647-653, 2012.

[129] M. I. da Costa Marinho, A. I. G. Costa, N. M. Vieira, M. C. G. Paiva, F. C. L. de Freitas, and A. A. da Silva, "Validation and application of a QuEChERS based method for estimation of half-life of imidazolinone herbicides in soils 
by LC-ESI-MS/MS," Ecotoxicology and Environmental Safety, vol. 167, pp. 212-217, 2019.

[130] A. Desmarchelier, J.-M. Oberson, P. Tella, E. Gremaud, W. Seefelder, and P. Mottier, "Development and comparison of two multiresidue methods for the analysis of 17 mycotoxins in cereals by liquid chromatography electrospray ionization tandem mass spectrometry," Journal of Agricultural and Food Chemistry, vol. 58, no. 13, pp. 7510-7519, 2010.

[131] C. Cavaliere, G. D’Ascenzo, P. Foglia, E. Pastorini, R. Samperi, and A. Laganà, "Determination of type B trichothecenes and macrocyclic lactone mycotoxins in field contaminated maize," Food Chemistry, vol. 92, no. 3, pp. 559-568, 2005.

[132] P. J. Fernandes, N. Barros, J. L. Santo, and J. S. Câmara, "High-throughput analytical strategy based on modified QuEChERS extraction and dispersive solid-phase extraction clean-up followed by liquid chromatography-triple-quadrupole tandem mass spectrometry for quantification of multiclass mycotoxins in cereals," Food Analytical Methods, vol. 8, no. 4, pp. 841-856, 2015.

[133] J. Rubert, Z. Dzuman, M. Vaclavikova, M. Zachariasova, C. Soler, and J. Hajslova, "Analysis of mycotoxins in barley using ultra high liquid chromatography high resolution mass spectrometry: comparison of efficiency and efficacy of different extraction procedures," Talanta, vol. 99, pp. 712-719, 2012.

[134] L. A. Berrueta, R. M. Alonso-Salces, and K. Héberger, "Supervised pattern recognition in food analysis," Journal of Chromatography A, vol. 1158, no. 1-2, pp. 196-214, 2007.

[135] J. Rubert, C. Soler, and J. Mañes, "Evaluation of matrix solidphase dispersion (MSPD) extraction for multi-mycotoxin determination in different flours using LC-MS/MS," Talanta, vol. 85, no. 1, pp. 206-215, 2011.

[136] A. B. Serrano, G. Font, M. J. Ruiz, and E. Ferrer, "Co-occurrence and risk assessment of mycotoxins in food and diet from Mediterranean area," Food Chemistry, vol. 135, no. 2, pp. 423-429, 2012.

[137] EC (European Communities), "European commission regulation (EC) no. 1881/2006 of 19 December, 2006. Setting maximum levels for certain contaminants in foodstuff," Official Journal of the European Union, vol. 364/5, pp. 5-24, 2006.

[138] G. Castellá, M. R. Bragulat, and F. J. Cabañes, "Fumonisin production by Fusarium species isolated from cereals and feeds in Spain," Journal of Food Protection, vol. 62, no. 7, pp. 811-813, 1999.

[139] C. Cavaliere, P. Foglia, C. Guarino et al., "Mycotoxins produced by Fusarium genus in maize: determination by screening and confirmatory methods based on liquid chromatography tandem mass spectrometry," Food Chemistry, vol. 105, no. 2, pp. 700-710, 2007.

[140] M. Weidenbörner, Encyclopedia of Food Mycotoxins, Springer Science \& Business Media, Berlin, Germany, 2001.

[141] Commission Decision, "Commission decision (EC) no. 2002/657 of 12 August 2002 implementing council directive $96 / 23 /$ EC concerning the performance of analytical methods and the interpretation of results," Official Journal of the European Communities, vol. 221, pp. 8-36, 2002.

[142] O. Lacina, M. Zachariasova, J. Urbanova, M. Vaclavikova, T. Cajka, and J. Hajslova, "Critical assessment of extraction methods for the simultaneous determination of pesticide residues and mycotoxins in fruits, cereals, spices and oil seeds employing ultra-high performance liquid chromatography-tandem mass spectrometry," Journal of Chromatography A, vol. 1262, pp. 8-18, 2012.

[143] C. Juan, A. Ritieni, and J. Mañes, "Determination of trichothecenes and zearalenones in grain cereal, flour and bread by liquid chromatography tandem mass spectrometry," Food Chemistry, vol. 134, no. 4, pp. 2389-2397, 2012.

[144] J. Barthel, C. Gottschalk, M. Rapp, M. Berger, J. Bauer, and K. Meyer, "Occurrence of type A, B and D trichothecenes in barley and barley products from the Bavarian market," Mycotoxin Research, vol. 28, no. 2, pp. 97-106, 2012.

[145] European Commission, "Commission recommendation of 17 August 2006 on the presence of deoxynivalenol, zearalenone, ochratoxin A, T-2 and HT-2 and fumonisins in products intended for animal feeding (2006/576/EC)," Official Journal of European Union, vol. 229, pp. 7-9, 2006.

[146] Y. Ren, Y. Zhang, S. Shao et al., "Simultaneous determination of multi-component mycotoxin contaminants in foods and feeds by ultra-performance liquid chromatography tandem mass spectrometry," Journal of Chromatography A, vol. 1143, no. 1-2, pp. 48-64, 2007.

[147] S. Amézqueta, E. González-Peñas, M. Murillo, and A. López de Cerain, "Validation of a high-performance liquid chromatography analytical method for ochratoxin A quantification in cocoa beans," Food Additives and Contaminants, vol. 21, no. 11, pp. 1096-1106, 2004.

[148] Y. Sugita-Konsihi, T. Tanaka, S. Tabata et al., "Validation of an HPLC analytical method coupled to a multifunctional clean-up column for the determination of deoxynivalenol," Mycopathologia, vol. 161, no. 4, pp. 239-243, 2006.

[149] E. Papp, H. Klara, G. Záray, and E. Mincsovics, "Liquid chromatographic determination of aflatoxins," Microchemical Journal, vol. 73, no. 1-2, pp. 39-46, 2002.

[150] M. Ventura, D. Guillen, I. Anaya et al., "Ultra-performance liquid chromatography/tandem mass spectrometry for the simultaneous analysis of aflatoxins B1, G1, B2, G2 and ochratoxin A in beer," Rapid Communications in Mass Spectrometry: An International Journal Devoted to the Rapid Dissemination of Up-To-The-Minute Research in Mass Spectrometry, vol. 20, no. 1, pp. 3199-3204, 2006.

[151] S. Monbaliu, C. Van Poucke, C. Van Peteghem, K. Van Poucke, K. Heungens, and S. De Saeger, "Development of a multi-mycotoxin liquid chromatography/tandem mass spectrometry method for sweet pepper analysis," Rapid Communications in Mass Spectrometry, vol. 23, no. 1, pp. 3-11, 2009.

[152] A. Y. Sirhan, G. H. Tan, and R. C. S. Wong, "Simultaneous detection of type $\mathrm{a}$ and type $\mathrm{b}$ trichothecenes in cereals by liquid chromatography coupled with electrospray ionization quadrupole time of flight mass spectrometry (LC-ESI-QTOF-MS/ MS)," Journal of Liquid Chromatography \& Related Technologies, vol. 35, no. 14, pp. 1945-1957, 2012.

[153] E. N. Ediage, C. van Poucke, and S. De Saeger, "A multianalyte LC-MS/MS method for the analysis of 23 mycotoxins in different sorghum varieties: the forgotten sample matrix," Food Chemistry, vol. 177, pp. 397-404, 2015.

[154] L. Hu and M. Rychlik, "Biosynthesis of ${ }^{15} \mathrm{~N}_{3}$-labeled enniatins and beauvericin and their application to stable isotope dilution assays," Journal of Agricultural and Food Chemistry, vol. 60, no. 29, pp. 7129-7136, 2012.

[155] J. L. Sørensen, K. F. Nielsen, P. H. Rasmussen, and U. Thrane, "Development of a LC-MS/MS method for the analysis of enniatins and beauvericin in whole fresh and ensiled maize," Journal of Agricultural and Food Chemistry, vol. 56, no. 21, pp. 10439-10443, 2008. 
[156] C. Falavigna, M. Cirlini, G. Galaverna, S. Sforza, A. Dossena, and C. Dall'Asta, "LC/ESI-MS/MS analysis outlines the different fumonisin patterns produced by F. verticillioides in culture media and in maize kernels," Journal of Mass Spectrometry, vol. 47, no. 9, pp. 1170-1176, 2012.

[157] B. Warth, A. Parich, J. Atehnkeng et al., "Quantitation of mycotoxins in food and feed from Burkina Faso and Mozambique using a modern LC-MS/MS multitoxin method," Journal of Agricultural and Food Chemistry, vol. 60, no. 36, pp. 9352-9363, 2012.

[158] N. Mahnine, G. Meca, M. Fernandez-Franzon, J. Manes, and A. Zinedine, "Occurrence of fumonisins B1, B2 and B3 in breakfast and infant cereals from Morocco," Phytopathologia Mediterranea, vol. 51, pp. 193-197, 2012.

[159] E. De Angelis, L. Monaci, M. Pascale, and A. Visconti, "Fate of deoxynivalenol, T-2 and HT-2 toxins and their glucoside conjugates from flour to bread: an investigation by highperformance liquid chromatography high-resolution mass spectrometry," Food Additives \& Contaminants: Part A, vol. 30, no. 2, pp. 345-355, 2013.

[160] E. Varga, T. Glauner, R. Köppen et al., "Stable isotope dilution assay for the accurate determination of mycotoxins in maize by UHPLC-MS/MS," Analytical and Bioanalytical Chemistry, vol. 402, no. 9, pp. 2675-2686, 2012.

[161] T. I. Ekwomadu, T. A. Dada, N. Nleya, R. Gopane, M. Sulyok, and M. Mwanza, "Variation of Fusarium free, masked, and emerging mycotoxin metabolites in maize from agriculture regions of South Africa," Toxins, vol. 12, no. 3, pp. 149-168, 2020.

[162] S. T. Tran and T. K. Smith, "Determination of optimal conditions for hydrolysis of conjugated deoxynivalenol in corn and wheat with trifluoromethanesulfonic acid," Animal Feed Science and Technology, vol. 163, no. 2-4, pp. 84-92, 2011.

[163] L. Freire and A. S. Sant'Ana, "Modified mycotoxins: an updated review on their formation, detection, occurrence, and toxic effects," Food and Chemical Toxicology, vol. 111, pp. 189-205, 2018.

[164] O. Vendl, C. Crews, S. MacDonald, R. Krska, and F. Berthiller, "Occurrence of free and conjugated Fusarium mycotoxins in cereal-based food," Food Additives \& Contaminants: Part A, vol. 27, no. 8, pp. 1148-1152, 2010.

[165] A. Malachova, Z. Dzuman, Z. Veprikova, M. Vaclavikova, M. Zachariasova, and J. Hajslova, "Deoxynivalenol, deoxynivalenol-3-glucoside, and enniatins: the major mycotoxins found in cereal-based products on the Czech market," Journal of Agricultural and Food Chemistry, vol. 59, no. 24, pp. 12990-12997, 2011.

[166] F. Q. Li, W. Wang, J. J. Ma, C. C. Yu, X. H. Lin, and W. X. Yan, "Natural occurrence of masked deoxynivalenol in Chinese wheat and wheat-based products during 2008-2011," World Mycotoxin Journal, vol. 5, no. 3, pp. 221-230, 2012.

[167] S.-T. Tran, T. K. Smith, and G. N. Girgis, "A survey of free and conjugated deoxynivalenol in the 2008 corn crop in Ontario, Canada," Journal of the Science of Food and Agriculture, vol. 92, no. 1, pp. 37-41, 2012.

[168] K. Lancova, J. Hajslova, J. Poustka et al., "Transfer of Fusarium mycotoxins and "masked" deoxynivalenol (deoxynivalenol-3-glucoside) from field barley through malt to beer," Food Additives \& Contaminants: Part A, vol. 25, no. 6, pp. 732-744, 2008.

[169] J. J. Sasanya, C. Hall, and C. Wolf-Hall, "Analysis of deoxynivalenol, masked deoxynivalenol, and Fusarium graminearum pigment in wheat samples, using liquid chromatography-UV-mass spectrometry," Journal of Food Protection, vol. 71, no. 6, pp. 205-1213, 2008.

[170] M. Suman, E. Bergamini, D. Catellani, and A. Manzitti, "Development and validation of a liquid chromatography/ linear ion trap mass spectrometry method for the quantitative determination of deoxynivalenol-3-glucoside in processed cereal-derived products," Food Chemistry, vol. 136, no. 3-4, pp. 1568-1576, 2013.

[171] C. Dall'Asta, G. Galaverna, G. Aureli, A. Dossena, and R. Marchelli, "A LC/MS/MS method for the simultaneous quantification of free and masked fumonisins in maize and maize-based products," World Mycotoxin Journal, vol. 1, no. 3, pp. 237-246, 2008.

[172] A. Faberi, P. Foglia, E. Pastorini, R. Samperi, and A. Laganà, "Determination of type B fumonisin mycotoxins in maize and maize-based products by liquid chromatography/tandem mass spectrometry using a QqQ linear ion trapmass spectrometer," Rapid Communications in Mass Spectrometry, vol. 19, no. 2, pp. 275-282, 2005.

[173] L. Hu, H. Liu, J. Yang et al., "Free and hidden fumonisins in raw maize and maize-based products from China," Food Additives \& Contaminants: Part B, vol. 12, no. 2, pp. 90-96, 2019.

[174] M. S. Oliveira, A. C. L. Diel, R. H. Rauber et al., "Free and hidden fumonisins in Brazilian raw maize samples," Food Control, vol. 53, pp. 217-221, 2015.

[175] M. Bryła, M. Roszko, K. Szymczyk, R. Jędrzejczak, and M. W. Obiedziński, "Fumonisins and their masked forms in maize products," Food Control, vol. 59, pp. 619-627, 2016.

[176] P. D. Andrade, R. R. Dantas, T. L. d. S. d. Moura-Alves, and E. D. Caldas, "Determination of multi-mycotoxins in cereals and of total fumonisins in maize products using isotope labeled internal standard and liquid chromatography/tandem mass spectrometry with positive ionization," Journal of Chromatography A, vol. 1490, pp. 138-147, 2017.

[177] J. W. Park, P. M. Scott, B. P.-Y. Lau, and D. A. Lewis, "Analysis of heat-processed corn foods for fumonisins and bound fumonisins," Food Additives and Contaminants, vol. 21, no. 12, pp. 1168-1178, 2004.

[178] M. Kostelanska, J. Hajslova, M. Zachariasova et al., "Occurrence of deoxynivalenol and its major conjugate, deoxynivalenol-3-glucoside, in beer and some brewing intermediates," Journal of Agricultural and Food Chemistry, vol. 57, no. 8, pp. 3187-3194, 2009. 